\title{
From understanding cellular function to novel drug discovery: the role of planar patch-clamp array chip technology
}

\author{
Christophe Py ${ }^{1}{ }^{*}$, Marzia Martina ${ }^{2}$, Gerardo A. Diaz-Quijada ${ }^{3}$, Collin C. Luk ${ }^{4}$, Dolores Martinez ${ }^{1}$, \\ Mike W. Denhoff ${ }^{1}$, Anne Charrier ${ }^{5}$, Tanya Comas ${ }^{2}$, Robert Monette ${ }^{2}$, Anthony Krantis ${ }^{6}$, Naweed I. Syed ${ }^{4}$ and \\ Geoffrey A. R. Mealing ${ }^{2}$
}

\author{
1 Institute for Microstructural Sciences, National Research Council of Canada, Ottawa, ON, Canada \\ 2 Institute for Biological Sciences, National Research Council of Canada, Ottawa, ON, Canada \\ ${ }^{3}$ Steacie Institute for Molecular Sciences, National Research Council of Canada, Ottawa, ON, Canada \\ ${ }^{4}$ Hotchkiss Brain Institute, University of Calgary, Calgary, AB, Canada \\ ${ }^{5}$ Centre Interdisciplinaire de Nanoscience de Marseille, Centre National de la Recherche Scientifique, Marseille, France \\ ${ }^{6}$ Centre for Research in Biopharmaceuticals and Biotechnology. University of Ottawa, Ottawa, ON, Canada
}

\section{Edited by:}

Ralf Franz Kettenhofen, Axiogenesis

AG, Germany

\section{Reviewed by:}

Niels Fertig, Nanion Technologies

$\mathrm{GmbH}$, Germany

John Michael Nagarah, California

Institute of Technology, USA

\section{*Correspondence:}

Christophe Py, Institute for

Microstructural Sciences, National

Research Council of Canada, Canada

1200 Montreal Road, Ottawa, ON,

Canada K1AOR6.

e-mail: christophe.py@nrc.ca
All excitable cell functions rely upon ion channels that are embedded in their plasma membrane. Perturbations of ion channel structure or function result in pathologies ranging from cardiac dysfunction to neurodegenerative disorders. Consequently, to understand the functions of excitable cells and to remedy their pathophysiology, it is important to understand the ion channel functions under various experimental conditions - including exposure to novel drug targets. Glass pipette patch-clamp is the state of the art technique to monitor the intrinsic and synaptic properties of neurons. However, this technique is labor intensive and has low data throughput. Planar patch-clamp chips, integrated into automated systems, offer high throughputs but are limited to isolated cells from suspensions, thus limiting their use in modeling physiological function. These chips are therefore not most suitable for studies involving neuronal communication. Multielectrode arrays (MEAs), in contrast, have the ability to monitor network activity by measuring local field potentials from multiple extracellular sites, but specific ion channel activity is challenging to extract from these multiplexed signals. Here we describe a novel planar patch-clamp chip technology that enables the simultaneous high-resolution electrophysiological interrogation of individual neurons at multiple sites in synaptically connected neuronal networks, thereby combining the advantages of MEA and patch-clamp techniques. Each neuron can be probed through an aperture that connects to a dedicated subterranean microfluidic channel. Neurons growing in networks are aligned to the apertures by physisorbed or chemisorbed chemical cues. In this review, we describe the design and fabrication process of these chips, approaches to chemical patterning for cell placement, and present physiological data from cultured neuronal cells.

Keywords: patch-clamp whole-cell recordings, planar patch-clamp chip, giga-seal, synaptic transmission, cultured neuron pair, cell placement, chemical patterning

\section{INTRODUCTION}

Neuronal functions - ranging for resting membrane potential, action potential propagation, transmitter release, synaptic transmission to plasticity-rely upon a variety of proteins embedded in the plasma membrane called ion channels. A common harbinger of many neurodegenerative diseases is the disruption of neural network activity caused by the impairment of synaptic function (Palop et al., 2006; Seeley et al., 2009). Per se, most drugs designed to treat neuronal pathologies are targeted toward ion channels (Conte Camerino et al., 2007). The search for novel therapeutic targets and the need for reliably predictive assessments of potential therapeutics are driving the demand for improved screening technologies against ion channels in cells that are synaptically connected (Stett et al., 2003a). Simple but physiologically relevant in vitro preparations, which are capable of modeling key aspects of brain function and are interfaced with a high-resolution functional interrogation system that permits high-throughput assessment at reasonable cost, need to be developed to address this demand.

The patch-clamp method developed by Nobel laureates Neher and Sakmann (1976) has proven to be the state of the art technique for high-resolution interrogation of electrophysiological activity. This technique consists in approaching a glass pipette, filled with a physiological saline solution and with a micron-sized tip aperture, to the surface of a cell and to isolate a "patch" of its membrane by forming a high resistance seal between the membrane and the perimeter of the aperture (cell-attached configuration; Figure 1A). 


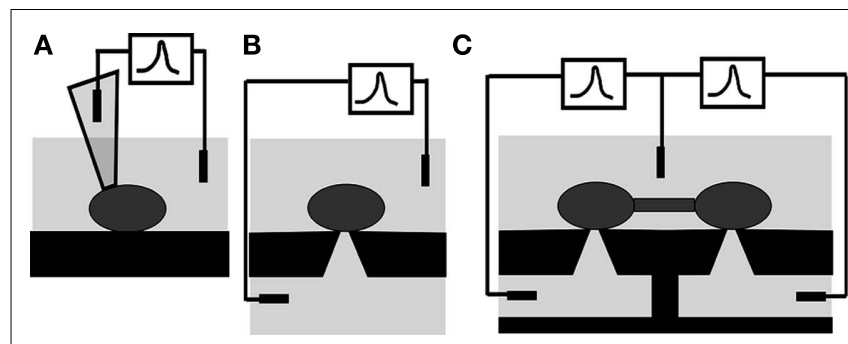

FIGURE 1 | Patch-clamp interrogation of neurons. (A) Conventional glass pipette. (B) Patch-clamp chip, with the tip of the pipette replaced by a micro-aperture in a self-supported film separating two baths. (C) Patch-clamp array chip, where several micro-apertures are etched in the self-supported film and the bottom bath is subdivided in microfluidic channels, one dedicated to each aperture. This novel structure can simultaneously interrogate cells in network communication. Taken from Py et al. (2008).

Using an amplifier connected to chlorate silver wires, one inserted in the glass pipette, the other in the culture bath, the activity of individual ion channels spanning the membrane patch can be recorded. The rupture of the membrane patch provides access to the intracellular space of the cell (whole-cell configuration), allowing the electrical access to ion channels populating the entire cell membrane. The patch-clamp approach is important as it allows direct visualization of microstates of single ion channel proteins, and how they are targeted by disease as well as drugs (Wang and Li, 2003). Most federal drug agencies mandate that patch-clamp data be provided for drugs that target ion channels. Additionally, any drug, regardless of its target, must be screened against certain ion channels to show that it does not perturb function of other organs/systems. The patch-clamp method has been refined and has led to techniques for high-resolution recording of current in excised membrane patches (inside-out and outside-out configurations; Hamill et al., 1981). Conventional patch-clamp requires highly qualified personnel and is labor intensive, making it slow and expensive, which limits its potential as a high-resolution interrogation tool for drug development assays.

Planar patch-clamp chips have been developed and refined over the last decade to specifically address the above limitation (Sigworth and Klemic, 2005; Behrends and Fertig, 2007). The tip of the pipette (Figure 1A) is replaced by a micron-sized aperture through a self-supported thin film (Figure 1B) separating an upper cell suspension chamber from an underlying "pipette" chamber. This chip is mounted in a two-chamber setup, the top one serving as the culture dish and the bottom one as the equivalent of the inside of the glass pipette. The cell is patched on the micrometer-sized aperture. The activity of the cell is measured through an amplifier connected to the recording electrode placed in the bottom chamber (subterranean microfluidic) and the reference electrode in the culture dish (Figure 1B).

This design makes the mechanized delivery of isolated cells in suspension to the aperture possible and, in combination with programmed seal detection and stimulation-recording routines, has led to the automation of patch-clamp. An alternative approach developed to increase the throughput of direct ion channel interrogation is the dual sharp electrode voltage-clamp system developed to record currents from ion channels over-expressed in oocytes (Schnizler et al., 2003). This process is also amenable to automation by using robotically controlled electrodes and assay chambers (Wang and Li, 2003). Automated patch-clamp and dual electrode voltage-clamp systems have been commercialized by several companies (Dunlop et al., 2008) and are now used to complement fluorometric imaging plate reader assays (Molecular-Devices-Corp ${ }^{1}$; Allenby et al., 2001) for high-throughput drug screening. These systems improve data throughput, a critical advantage for primary drug screening. However, the technique is predominantly used to study ion channels over-expressed in non-neuronal cell lines and is restricted to isolated cells lacking synaptic communication, resulting in models of questionable biological relevance mostly inadequate for secondary screening. Since the majority of drugs acting on ion channels target synaptic transmission, interrogation of individual cells at multiple sites in communicating networks has enormous potential for pharmaceutical assays.

Multielectrode arrays (MEAs) allow interrogation of activity in communicating networks of neurons using cell culture, brain slice, or in vivo preparations (Taketani and Baudry, 2006; Jones et al., 2011) by sensing extracellular field potentials from proximal cells. MEAs are powerful and readily available tools to monitor the activity of networks of neurons and their perturbations by diseases or drugs (MEA Meeting, 2010). Commercially available MEAs (AlphaMED ${ }^{2}$; Axion-Biosystems ${ }^{3}$; Ayanda $^{4}$; Multi-Channel-Systems ${ }^{5}$ ) typically incorporate up to a few hundred electrodes, permitting recording of passive and stimulated electrophysiological activity from various sized windows within a neuronal network with varying spatial resolution (typically 30$100 \mu \mathrm{m})$. More recently, field-effect transistor array technology (Fromherz et al., 1991; Fromherz, 2003; Patolsky, 2007; Frey et al., 2009) has allowed the integration of up to 16,384 electrodes with sub-cellular spatial resolution (Lambacher et al., 2004), although this platform is not yet commercially available (Graham et al., 2011) and data analyses are daunting. Furthermore, progress in nanotechnology has allowed the development of lower impedance electrodes resulting in remarkable improvements in signal-tonoise ratios (Ben-Jacob and Hanein, 2008; Huys et al., 2008; Hai et al., 2010). Despite these advances, intracellular control, and notably voltage- and current-clamp, is not possible using MEA technology, and specific information pertaining to ion channel activity is challenging to extract from multiplexed signals.

The majority of drugs acting on ion channels targets synaptic transmission (Conte Camerino et al., 2007). Consequently, a tool which provides a high-resolution patch-clamp interrogation of individual cells at multiple sites in communicating networks has enormous potential for pharmaceutical assays to investigate in vitro models of disease, as well as neuronal physiology and synaptic plasticity. A planar patch-clamp array technology that combines key benefits of both conventional patchclamp and MEAs on a chip has been proposed (Mealing et al.,

\footnotetext{
${ }^{1} \mathrm{http}: / /$ www.moleculardevices.com/Products/Instruments/FLIPR-Systems.html ${ }^{2}$ http://www.med64.com/

${ }^{3}$ http://www.axionbiosystems.com/

${ }^{4} \mathrm{http}: / /$ www.ayanda-biosys.com/

${ }^{5} \mathrm{http}: / /$ www.multichannelsystems.com/
} 
2005a,b; Py et al., 2008). In this concept, individual neurons are probed through apertures that connect to dedicated subterranean microfluidic channels (Figure 1C), allowing the simultaneous high-resolution patch-clamp interrogation of individual cultured neurons at multiple sites in communicating networks. Cells are first aligned to these apertures by patterned chemical adhesion or guidance cues and can subsequently form synaptic connections. This patch-clamp array chip offers the opportunity to develop more physiologically relevant in vitro models, extract unique information on brain function and network communication from them, and better predict therapeutic efficacy, notably as it pertains to synaptic physiology.

Two novel designs have been developed: a single aperture chip fabricated on a silicon platform and a two apertures chip constructed by laminating a polyimide film on a silicone plastic substrate in which the two apertures are connected to independent subterranean microfluidic channels. Proof-of-concepts have been demonstrated using synaptically connected snail neurons cultured over both chips. Preliminary data using primary cortical neurons cultured directly on the chip surface suggest that interrogation of synaptically communicating mammalian neurons on a patch-clamp chip is possible. In this review we describe and discuss the design and fabrication of these chips (see Chips Fabrication) and the experiments conducted to demonstrate the validity of both designs (see Proof-of-Concept for Si and PI Chips). Parameters controlling the formation of a tight cell to aperture seal (giga-seal) are discussed. Cell placement and adhesion strategies, essential to develop cultured in vitro networks and eliminate the need for manual manipulation of cells are also described (see Cell Placement).

\section{CHIPS FABRICATION}

\section{CHIP MATERIALS PLATFORMS}

The first planar patch-clamp devices were fabricated in silicon (Hediger et al., 1999; Fertig et al., 2000; Schmidt et al., 2000); the material was also machined to mimic the tip of a micropipette (Lehnert et al., 2002; Stett et al., 2003b). Quartz or glass (Fertig et al., 2001, 2003), polydimethyl siloxane (PDMS or silicone; Klemic et al., 2002, 2005), and polyimide (Stett et al., 2003c) patchclamp chips were subsequently designed to overcome the high capacitive coupling between the culture media and the measuring media resulting through the semiconductive silicon substrate. The convenient molding properties of PDMS inspired lateral-patch chips with integrated fluidic channels for the delivery of cell suspensions (Seo et al., 2004; Ionescu-Zanetti et al., 2005; Chen and Folch, 2006; Lau et al., 2006; Ong et al., 2007; Tang et al., 2010). Still, the advantages of silicon as a material are considerable. Silicon micromachining is well understood thanks to its pervasive use for microelectronics applications and its offshoot in MicroElectro-Mechanical Systems (MEMS; Gad-el-Hak, 2001), so large quantities of chips can be produced with very high yield and critical process control. This is a significant advantage compared to competing technologies. Additionally, silicon is attractive for the integration of multiple functionalities, such as on-chip amplification (Kaul et al., 2004; Aziz et al., 2007), and which could extend to other co-located sensors using conventional MEMS technology. For these reasons, several groups have still chosen silicon as a platform for patch-clamp chips in recent years (Pandey et al., 2004; Pantoja et al., 2004; Picollet et al., 2004; Matthews and Judy, 2006; Curtis et al., 2008; Sordel et al., 2010); likewise, we have developed a similar design consisting of a single aperture in a suspended silicon nitride/silicon dioxide film stack on silicon for single site recording. We refer to it as the silicon (Si) chip in this review.

Unfortunately, the integration of multiple apertures on-chip, each with a dedicated subterranean microfluidic channel, proved problematic in silicon. For the film in which the micro-aperture is machined to be supported by the substrate, the microfluidic channels must be coupled to apertures on its underside. The micro-aperture is connected to the bottom "pipette" chamber through a well which in our process has a pyramid shape with a fixed angle determined by the anisotropic wet etch of silicon. The well could have straight walls if dug by deep reactive ion etching instead, but the pyramid shape is desirable as it lowers the access resistance of the chip. However, it also limits the capacity to integrate apertures to at least several hundred microns - more than the optimal distance between neurons in a cultured network. A favored fabrication method is therefore to transfer the thin film containing the apertures away from the wafer on which they are machined to the top of the microfluidic channels, which can thus be integrated much closer. As a proof of our concept, we chose to integrate a polyimide (PI) thin film on top of a PDMS microfluidic chip. The latter was chosen for its convenient and reliable method of fabrication by replication (Qin et al., 2010); the former because of its cytocompatibility (Stett et al., 2003c), high chemical and mechanical stability, and its low dielectric constant. Additionally, polyimide processing techniques are standard in the microelectronics industry; polyimide films have been laminated to fabricate microfluidic devices (Metz et al., 2001) and in particular perforated MEAs (Egert et al., 2005). In this review we refer to that second generation chip as the polyimide (PI) chip.

\section{ONE-APERTURE SILICON CHIP}

The fabrication process was previously described in detail (Py et al., 2010) and is adapted from (Schmidt et al., 2000); it is schematically represented in Figure 2. It is carried out on $150 \mathrm{~mm}$ double-side polished (100) silicon wafers at the Canadian Photonics Fabrication Centre ${ }^{6}$. The membrane separating the culture media from the measuring media must have a high dielectric rigidity, and the small dimension of the aperture requires the membrane to also be thin and mechanically strong enough so that it can be suspended. We chose a $1-\mu \mathrm{m}$ thick silicon nitride film rather than silicon dioxide for its superior mechanical strength and inertness to the potassium hydroxide $(\mathrm{KOH})$ solution used for bulk micromachining of silicon (step c). A low-pressure chemical vapor deposition (LPCVD) process was optimized for low stress coating of silicon nitride.

After deposition, $4 \mu \mathrm{m}$ apertures were opened (step a) in the silicon nitride layer by lithography and reactive ion etching. A second lithography and etching step at the back of the wafer (step b) opened large windows in the silicon nitride along $<100>$ Si crystallographic axes and centered with the apertures on the top side. The

\footnotetext{
${ }^{6} \mathrm{http}: / / \mathrm{cpfc}-\mathrm{ccfdp} . n r c-c n r c . g c . c a /$
} 


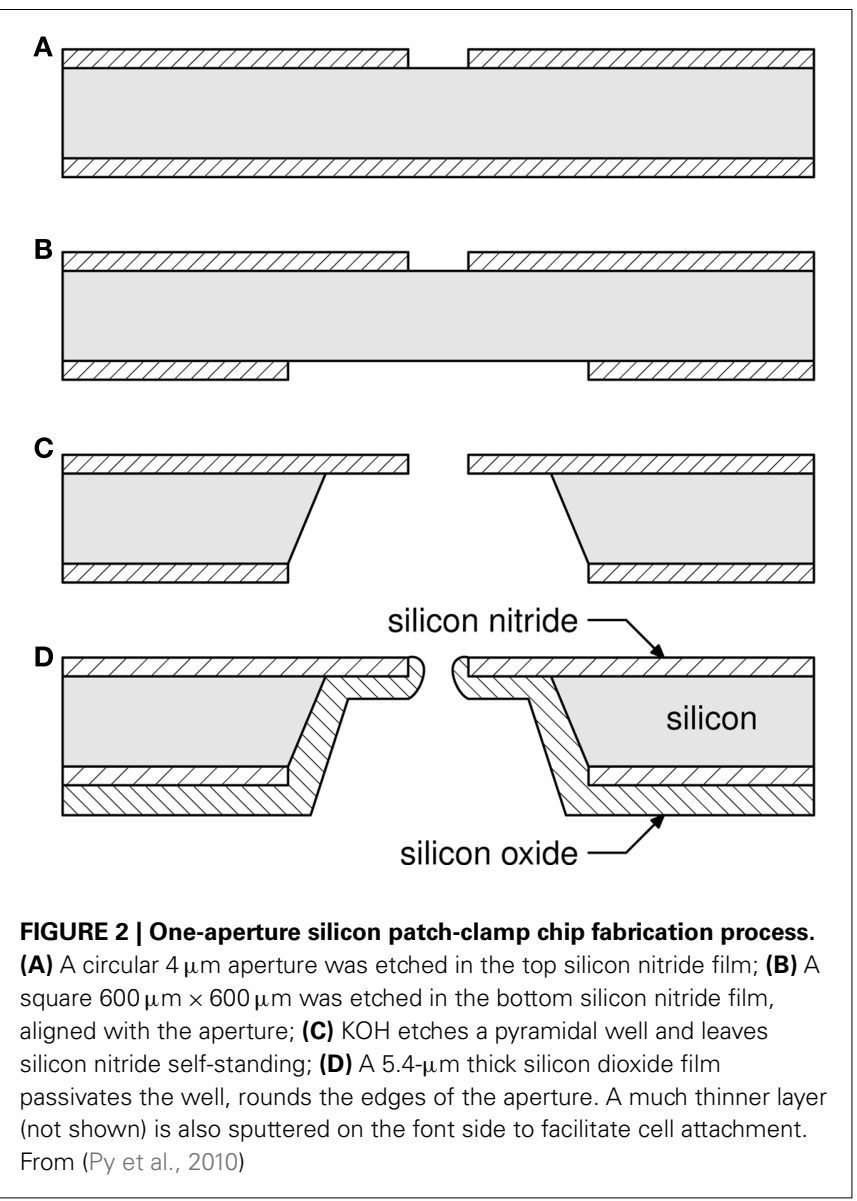

silicon bulk was then anisotropically etched in a hot $\mathrm{KOH}$ solution (step c), resulting in an inverted truncated pyramid-shaped well and a $100 \times 100-\mu \mathrm{m}^{2}$ membrane in the silicon nitride film where the aperture had been patterned. The $\mathrm{KOH}$ etch left bare silicon walls in the well which were passivated by depositing a $5.4-\mu \mathrm{m}$ thick low stress plasma-enhanced chemical vapor deposition silicon dioxide film (step d). The coating reduced the diameter of the aperture by $2 \mu \mathrm{m}$ while rounding its edges. Finally, a $0.1-\mu \mathrm{m}$ thick silicon dioxide film was deposited by the same method on the front side of the wafer. Surface functionalization was found to be more successful on that surface than on silicon nitride, which we hypothesize is due to a lower concentration of silanol groups on our silicon nitride surfaces. It is well known that the structure and therefore concentration of silanol groups in silicon nitride surfaces varies considerably and is difficult to control (Hamblin et al., 2007). The resulting surfaces were smooth, with a roughness measured by atomic force microscopy to be $6-8$ Åover a $1-\mu \mathrm{m}^{2}$ area. There is mounting evidence that aperture size, morphology, and smoothness are important factors to obtain a high proportion of high quality cell to aperture seals (Sordel et al., 2006; Lehnert et al., 2007; Curtis et al., 2008; Chen et al., 2009; Nagarah et al., 2010). We have provided the first visual evidence of an intimate cell to aperture interaction (Py et al., 2011), see Figure 3.

Each $150 \mathrm{~mm}$ wafer produced about one hundred fifty $1 \mathrm{~cm}^{2}$ chips, and a yield higher than $90 \%$ was routinely achieved in several batches. Wafers were easily diced into chips using grooves patterned in the well etching step.

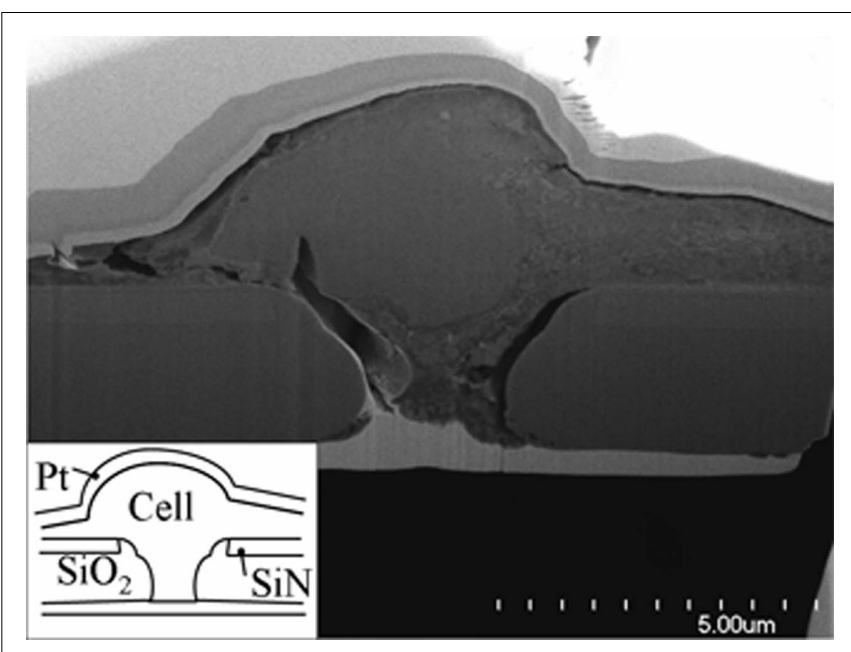

FIGURE 3 | Scanning Electron Micrograph of a focused ion beam section of a cultured $\mathrm{P} 19$ cell over an aperture in a $\mathrm{SiN} / \mathrm{SiO}_{2}$ stack membrane (see insert). To avoid damage during sectioning, the assembly is sandwiched between two platinum (light gray) layers. While somewhat damaged during fixing, the cell visibly lowers into the rounded conical aperture. Adapted from Py et al. (2011).

Various fluidic interfaces have been developed to allow perfusion and cell culture (Li et al., 2006; Matthews and Judy, 2006; Morales et al., 2008; Alberti et al., 2010; Chen et al., 2011). Our chips were mounted in packages machined at low cost from Plexiglas $\mathrm{G}$ sheets. The packages consist of a $16 \mathrm{~mm}$ diameter, $6 \mathrm{~mm}$ deep culture chamber at the bottom of which the chip is glued in a square recess. Under the membrane of the chip, a $1.5-\mathrm{mm}$ diameter hole connects the chip to subterranean fluidic conduits opened on each side of the chip to allow easy perfusion of the physiological saline solution or other chemicals. Packages were cleaned with isopropanol in an ultrasonic bath and $1.5 \mathrm{~mm}$ glass tubes were glued at each end of the subterranean fluidic circuit to be fitted with silicone tubing for perfusion. Two rings of Dow Corning RTV silicone 3140 glue were necessary to avoid leaks and minimize the shunt capacitance of the chip, nominally $17 \mathrm{pF}$. Our design achieves this comparatively low value thanks to the thick silicon dioxide back coating, rather than by limiting the contact surface on the cell culture side (Pantoja et al., 2004; Matthews and Judy, 2006), which somewhat restricts the interrogated biological model. It is, however, still higher than the typical $1-10 \mathrm{pF}$ of a glass pipette (Hamill et al., 1981; Zhou and Kang, 2000). This disadvantage is compensated by the fact that the access resistance, at approximately $1.5 \mathrm{M} \Omega$ for a typical $150 \mathrm{mM}$ Phosphate Buffered Saline (PBS) solution, is much lower than the typical 5-10 M $\Omega$ access resistance of a glass pipette. Packaged chips were sterilized in an air plasma cleaner for $15 \mathrm{~min}$. The process also oxidizes all surfaces, facilitating fluidic loading. To avoid trapping bubbles, a pressure of $1 \mathrm{~atm}$ is typically applied in the subterranean fluidics while loading the physiological solutions.

\section{TWO APERTURES POLYIMIDE CHIP}

Figure 4A presents a micrograph of the chip: the top PI membrane ( $3 \mu \mathrm{m}$ thick, transparent) contains two $3 \mu \mathrm{m}$ round apertures spaced $50 \mu \mathrm{m}$ apart and individually accessible through the 
A

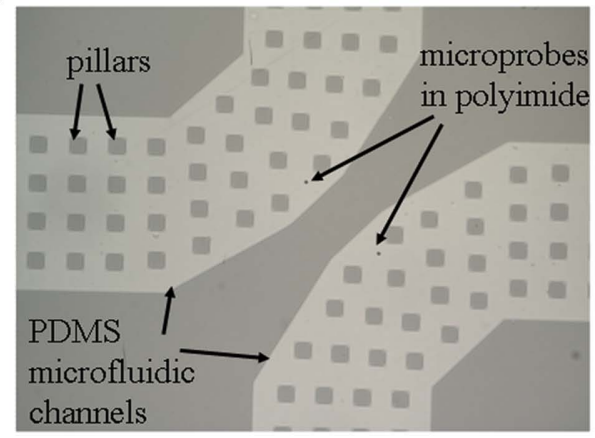

B

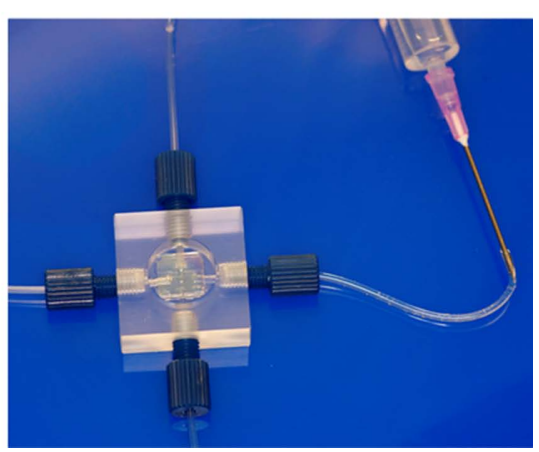

FIGURE 4 | Two-aperture transparent PI-PDMS chip. (A) Scanning electron micrograph showing the two apertures, each with a dedicated microfluidic channel for perfusion and measurement, seen through the transparent PI film in lighter gray. The channels are supported by many square pillars part of the PDMS structure. (B) The chip is packaged in a Plexiglas enclosure with a top cell culture vial and a dedicated input and output for each aperture. Figure 4A adapted from Martinez et al. (2010). bottom PDMS microchannels (each $200 \mu \mathrm{m}$ wide and $10 \mu \mathrm{m}$ deep, also transparent). Square pillars $(20 \mu \mathrm{m} \times 20 \mu \mathrm{m})$ are integrated in the microchannels as support for the thin PI film. Four via holes punched through the PDMS at the extremities of the microchannels allow perfusion of chemicals and electrophysiological probing in the underlying fluidics (not seen on the picture). The chip is packaged in a machined Plexiglas culture chamber with aligned inlets and outlets (Figure 4B), allowing easy perfusion of the physiological saline solution or other chemicals.

To minimize capacitance, the choice of a polymer membrane with a low dielectric constant is obviously advantageous. The shunt capacitance is also proportional to the section of the microfluidic channels and the inverse of the PI thickness. The access resistance is the resistance of the aperture plus that of the microfluidic channel. The former is directly proportional to the PI membrane thickness and the latter is inversely proportional to its section. Increasing the thickness of the PI film will thus decrease the shunt capacitance but increase the access resistance. The access resistance and shunt capacitance are however minimized independently by designing deep and narrow microfluidic channels, respectively. The dimensions described above result in $7.7 \mathrm{pF}$ shunt capacitance, similar to a glass pipette, and an access resistance of $1.6 \mathrm{M} \Omega$ for a $150 \mathrm{mM}$ PBS solution, in agreement with modeling and similar to the $\mathrm{Si}$ chip. These values make the microchip capable of high fidelity patch-clamp recording (Sigworth and Klemic, 2005).

Figure 5 presents a schematic of the polymer microchip fabrication, detailed in a previous publication (Martinez et al., 2010b). The two layers forming the chip, PDMS and PI, were processed independently starting from $2^{\prime \prime}$ Si wafers and bonded with alignment, producing nine $1 \mathrm{~cm} \times 1 \mathrm{~cm}$ chips. PDMS microchannels were fabricated by replica-molding from a SU8-on-Si master mold. Shrinking of the replicated PDMS during curing was found to be irreproducible, making wafer level assembly over several centimeters impossible. Multilayer soft-lithography techniques were developed a decade ago to fabricate microfluidic components (Unger et al., 2000). To reduce PDMS shrinking variations, we used a variation of that technique as depicted in Figure 5, steps 1a to $1 \mathrm{~d}$. A first thick PDMS slab was obtained by curing a Sylgard 184 resin mixture and curing it for $3 \mathrm{~h}$ cure at $120^{\circ} \mathrm{C}$ (step 1a). A

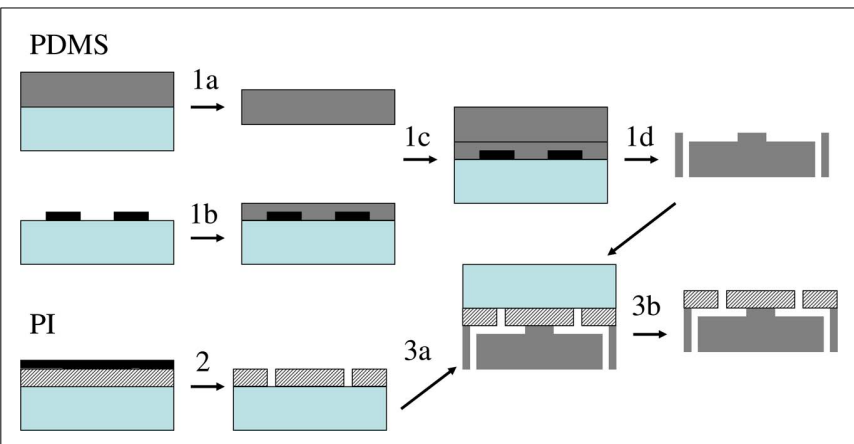

FIGURE 5 | PI-PDMS chip fabrication process. PDMS (dark gray, step 1) and PI (hatched, step 2) are processed independently on 2" Si wafers (light green); alignment-bonding (step 3a) and release (step 3b) form the final microchip. Adapted from Martinez et al. (2010).

second thinner layer was spin coated on the SU8-on-silicon master, producing a thin structure containing the microchannels. After a 5 -min partial cure on a hot plate at $95^{\circ} \mathrm{C}$ (step $1 \mathrm{~b}$ ), thin and thick PDMS layers were covalently bonded following plasma treatment of both surfaces (step 1c). The resulting PDMS chip was peeled from the SU8-on-Si mold and fully cured. The thick PDMS slab acted as a support for the thin PDMS containing the microchannels, resulting in microstructures with minimized shrinking variations (to $6 \pm 4 \mu \mathrm{m}$ over $1 \mathrm{~cm}$ compared to $138 \pm 13 \mu \mathrm{m}$ over $1 \mathrm{~cm}$ without the thick pre-cured support), low enough to allow alignment-bonding to the upper PI layer at the wafer level. Fluidics access via holes were punched in the PDMS at both ends of both channels using a machined syringe needle (step 1d), producing $200 \mu \mathrm{m}$ diameter via holes.

A 3- $\mu \mathrm{m}$ thick PI film was spun on a Si wafer and cured in three stages up to $350^{\circ} \mathrm{C}$, and an aluminum mask layer was evaporated on the PI film (step 2a). Apertures were defined by lithography in the aluminum mask, oxygen reactive ion etching transferred them to the PI, and the residual aluminum was removed in a metal etchant (step 2). To facilitate bonding, an adhesion promoter was spun on the PI layer, and the PDMS wafer was treated in air plasma. PI and PDMS wafers were aligned and bonded in a M9 flip-chip bonder 
(step 3a). The assembly was heated at $65^{\circ} \mathrm{C}$ for $2 \mathrm{~h}$ and peeled from the Si substrate supporting the PI film (step 3b). Wafers were diced in nine $1 \mathrm{~cm} \times 1 \mathrm{~cm}$ chips, which were then bonded to a lower glass support and glued to a machined Plexiglas package fitted with connectors for easy microchannel access (see Figure 4B). After 5 min sterilization in an air plasma cleaner, microfluidic channels were filled with the electrophysiological recording solution.

\section{PROOF-OF-CONCEPT FOR Si AND PI CHIPS CELL PREPARATION}

Testing and validation of both generations of chips has been accomplished (Martinez et al., 2010b; Py et al., 2010; Martina et al., 2011) through a series of patch-clamp experiments conducted using a well characterized Lymnaea neuron model. The Lymnaea stagnalis preparation was selected because of the ease with which its well characterized neurons can be positioned and cultured. Due to the significantly smaller central nervous systems of Lymnaea and larger soma of their neurons, this simple model approach is more amenable to cellular analysis than its mammalian counterparts. Moreover, the innate propensity of individually isolated neurons to re-form proper synaptic connections with exquisite accuracy in vitro make it ideal to study the mechanisms underlying synaptic formation and transmission. The soma-soma model has been established, where identified preand post-synaptic neurons juxtaposed in culture re-form proper synaptic connections seen in vivo without requiring neuronal outgrowth (Feng et al., 1997; Hamakawa et al., 1999; Woodin et al., 1999, 2002). This circuit is known to form an excitatory cholinergic synapse between pre-synaptic respiratory neuron Visceral Dorsal 4 (VD4) and post-synaptic Left Pedal Dorsal 1 (LPeD1) neurons (Feng et al., 1997). The neurons have specifically characterized (from genes to molecules) both cholinergic and dopaminergic networks that mediate the neural control of breathing in this model, and these networks have been reconstructed in cell culture (Bell and Syed, 2009). Importantly, it has been demonstrated that the dopaminergic and cholinergic networks function in a manner similar to that of vertebrates. Therefore, understanding the fundamental principles behind synaptic communication in this model is relevant to understanding neurodegenerative and neurodevelopmental disorders - at a resolution unattainable in most vertebrate models. Moreover, fundamental mechanisms of neuronal communications revealed in this simple model are directly applicable to their vertebrate counterparts. Experiments using mammalian primary cortical neurons are also being performed in our laboratories. Preliminary current-clamp recordings obtained from a 14 days old primary cortical culture have been obtained with a Si chip (Martinez et al., 2010a). This result is encouraging and suggests that chip application to mammalian cells is a realistic objective that could be reliably achieved.

\section{PATCH-CLAMP RECORDINGS FROM LYMNAEA NEURONS}

Lymnaea neurons (VD4 and LPeD1) were manually positioned over the apertures of $\mathrm{Si}$ and PI chips and cultured at room temperature for a minimum of $2 \mathrm{~h}$ (Martinez et al., 2010b; Py et al., 2010) or 8-12 h to establish synaptic communication (Martina et al., 2011). The cells were found to be viable and maintained their electrophysiological properties. Whole-cell recordings were obtained over prolonged periods of time. Most neurons were tested only once over a period of 20-40 min, but some neurons were re-tested several hours after the initial analysis and found to behave in similar fashion. High quality recordings in current- and voltage-clamp were achieved with both $\mathrm{Si}$ and PI chips (Martinez et al., 2010b; Py et al., 2010; Martina et al., 2011). Specifically, the first action potential recordings ever recorded from neurons cultured on a patch-clamp chip (Figure 6), voltage-clamp induction of whole-cell ion channel currents with exceptional fidelity (Figure 8) and post-synaptic recordings from neurons communicating through synaptic connections and evidence of synaptic plasticity (Figures 7 and 8), were all obtained.

In particular, the suitability of chips in obtaining meaningful physiological data and describing a network behavior have been achieved by recording from synaptically connected neurons cultured on the chips and manipulating the post-synaptic responses in the VD4-LPeD1 system. The Lymnaea model have been described to develop cholinergic excitatory synapses between VD4 and LPeD1 neurons (Woodin et al., 1999) and the addition of tubo-curarine $(100 \mu \mathrm{M})$, a cholinergic receptor antagonist, to the bath solution blocked the excitatory post-synaptic potentials (EPSPs) in LPDe1 (Figure 7C), confirming that the synaptic transmission between the pair is cholinergic.

Synaptic plasticity is a fundamental process in learning and memory, and its impairment is associated with numerous neuropathologies. Our chips make it possible to reproduce in vitro the fundamental mechanism of synaptic transmission. This is pivotal in the testing and screening of drugs acting on ion channels involved in synaptic transmission and plasticity. Synaptically connected VD4 and LPeD1 neurons have also been reported to show a transient potentiation in synaptic transmission following tetanic stimulation of the pre-synaptic neuron (Luk et al., 2011). To verify the reproducibility of this event on chips, brief burst of action potentials in VD4 neuron were applied (8-15 action potentials at 5-10 Hz), generated by a continuous depolarizing current injection using a sharp electrode and responses were recorded from the post-synaptic LPeD1 neuron on-chip in both current- and

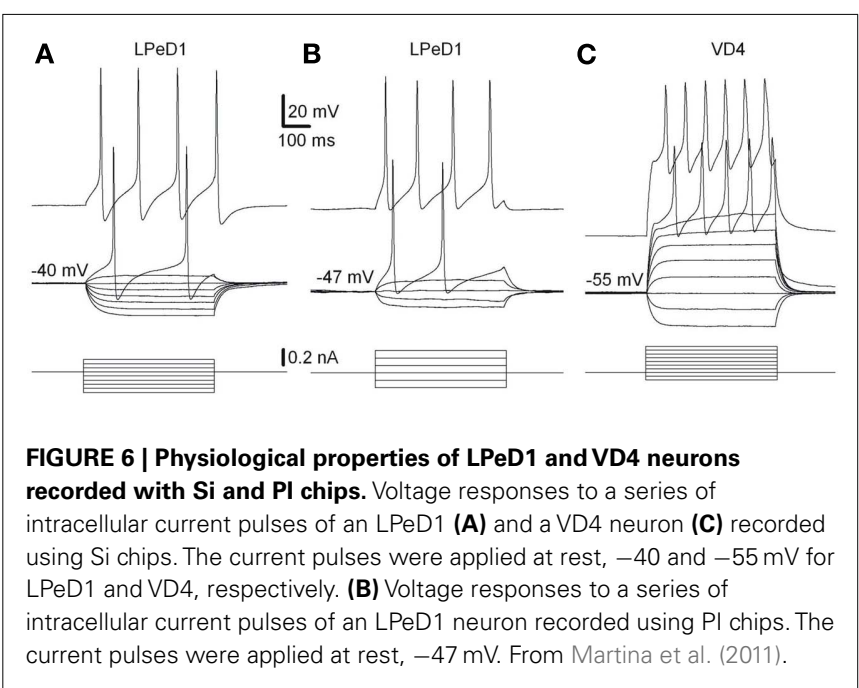


A

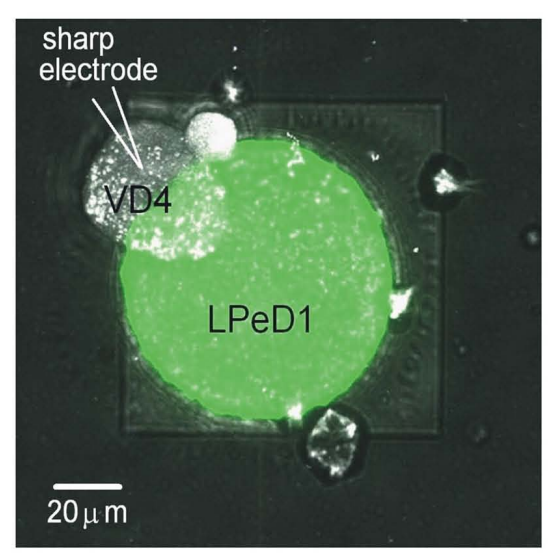

B

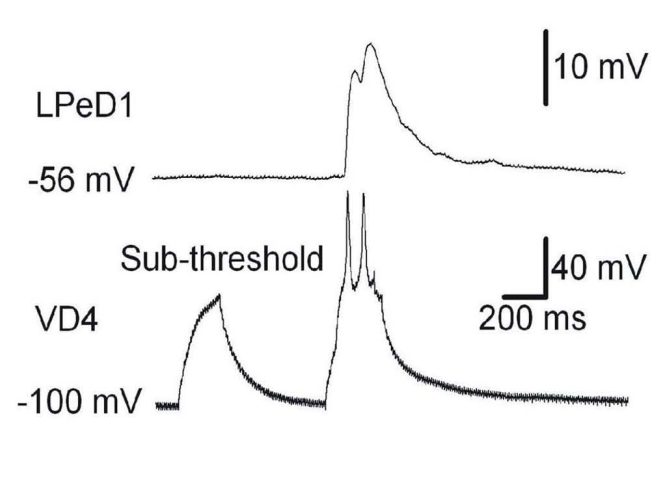

C

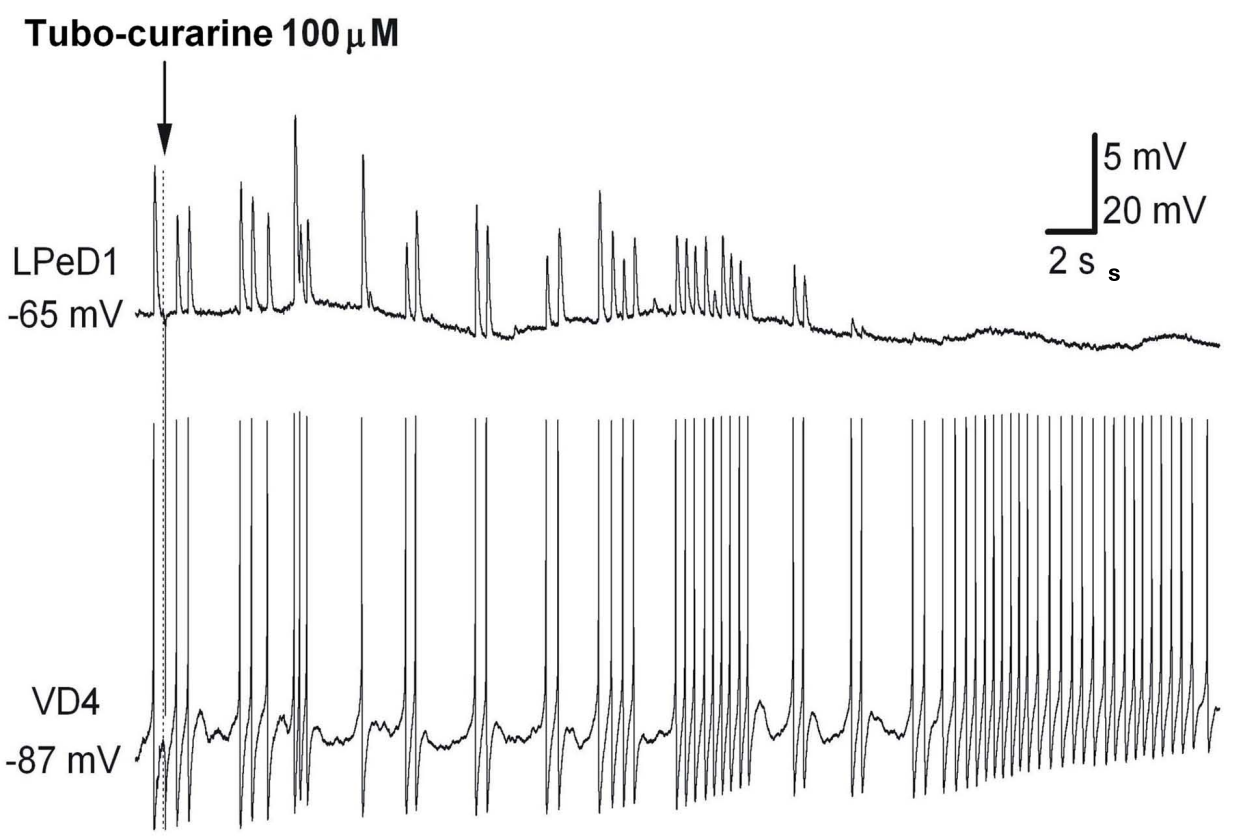

FIGURE 7 | Cultured LPeD1 and VD4 neurons forming a soma-soma synapse on a Si chip. (A) Superposition of reflected light and fluorescence confocal imaging of a Si chip with an LPeD1 neuron plated over the aperture and forming a soma-soma synapse with a VD4 neuron. Subterranean fluidics were filled with a recording solution containing a green dye. (B) Simultaneous whole-cell recordings in current-clamp mode of an LPeD1 (patch-clamp) and a VD4 neuron (sharp electrode). Sub-threshold stimulation of the pre-synaptic VD4 neuron does not evoke any response in the post-synaptic LPeD1 neuron, but above-threshold stimulation does. (C) Turbo-curarine is shown to suppress the responses evoked in the LPeD1 neuron while stimulating the VD4 neuron. From Martina et al. (2011). voltage-clamp modes (Figures $\mathbf{8 A , B}$, respectively). The amplitudes of EPSPs, evoked by single action potentials in the pre-synaptic cell, were transiently increased following burst stimulation (Figure 8A, red line), suggesting the induction of potentiation in the LPeD1 neuron. The same phenomenon was also examined in voltageclamp mode, and excitatory post-synaptic currents (EPSCs) are shown in Figure 8B.

\section{DOUBLE PATCH-CLAMP RECORDINGS}

A current limitation of the Si chip design is its single recording aperture, which confined on-chip acquisition to post-synaptic responses, relying on an external electrode for pre-synaptic stimulation and recording. PI chips were developed to overcome that limitation and enable simultaneous patch-clamp recordings from neuron pairs. Double simultaneous recordings have been described using PI chip and VD4-LPeD1 neurons (Figure 9). However, while each neuron was independently excitable, they did not propagate a synaptic response, suggesting that no synapse was present between the two neurons. Synapse formation requires interaction between specialized pre-synaptic and postsynaptic intracellular machinery. Cell-cell signaling (Scheiffele, 2003), intrinsic cell-cell interactions involving activity-dependent 


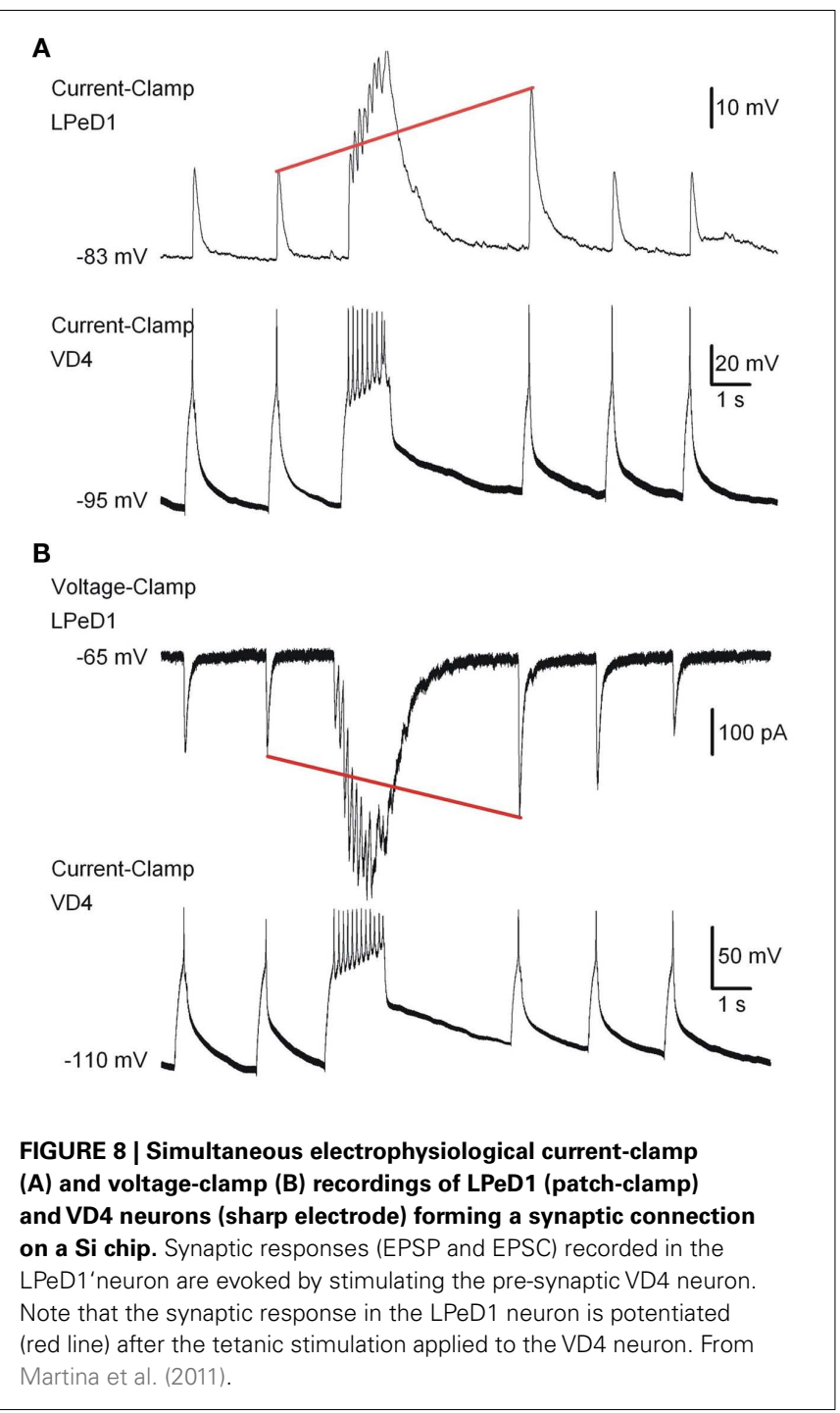

mechanisms (Shatz, 1990; Katz and Shatz, 1996; Dan and Poo, 2004), and extrinsic molecules present in the extracellular milieu (Vicario-Abejo'n et al., 1998; Craig et al., 2006), are all critical for the establishment, maturation, and remodeling of synapses. The absence of functional synapses on PI chips may have been due to increased cytoplasmic dialysis resulting from the larger apertures on PI chips (see Giga-seal Formation and Success Rate of Recordings), particularly affecting the smaller VD4 neurons.

To observe VD4 and LPeD1 plated on the chips, cytoplasmic perfusion of these neurons was accomplished via the subterranean microfluidics of the PI chip with two different dyes (Figures 7A and 9). In both Si and PI chips, these neurons displayed no change in resistance following dye loading, indicating that microfluidic perfusion did not compromise seal integrity. Figure 9 shows a confocal 3-D reconstruction of a VD4/LPeD1 neuron pair (VD4 in red; LPeD1 in green) cultured on a PI chip. This capability could be advantageous to studies of signaling molecules where intracellular delivery of compounds or dyes is required.

It is noteworthy that in our Lymnaea neuron model, the synapses are formed between the soma which in turn sit on top of the chip apertures, providing direct and controlled access to synaptic sites. The combination of these chips and cell model thus allows us to record and monitor synaptic currents without space clamp errors.

\section{GIGA-SEAL FORMATION AND SUCCESS RATE OF RECORDINGS}

In the glass pipette patch-clamp approach, the formation of a gigaseal $(>1 \mathrm{G} \Omega$ ) between the cell membrane and the patch pipette is critical and has been extensively studied (Sachs and Qin, 1993; Priel et al., 2007; Suchyna et al., 2009). Similarly, planar patchclamp technology depends upon formation of a highly resistive seal between the cell membrane and the circumference of an onchip aperture feature. Planar patch-clamp chips reported to date have used isolated cells in suspension, and rely on suction to draw cells to the aperture to form a giga-seal. Consequently, unlike conventional patch-clamp, planar patch-clamp technology has not been used to interrogate cultured cells, which precludes their use for the analysis of synaptic communication. Giga-seal formation with our chips occurs mostly spontaneously while neurons are establishing in culture and does not rely on suction (Ong et al., 2006). The quality of the giga-seal is directly linked to the success rate in chip recordings. In Table 1, the success rates for VD4 and LPeD1 neurons using Si and PI chips are summarized.

Several factors warrant consideration in giga-seal formation:

(1) Aperture geometry. It has previously been reported that a rounded hourglass profile maximizes contact with the cell membrane and facilitates seal formation on planar patchclamp chips (Sordel et al., 2006; Lehnert et al., 2007; Curtis et al., 2008; Chen et al., 2009), while an impressive $80 \%$ of giga-seals have been recently reported for a cell line with a conical profile (Nagarah et al., 2010). Si chips have circular $2 \mu \mathrm{m}$ diameter rounded conical apertures (Figure 3) and meaningful cell connections were obtained in $58 \%$ of cases. By contrast, the PI chips have substantially square opening with $3 \mu \mathrm{m}$ sides, and a $35 \%$ success rate was obtained. The square shape of the aperture may induce damage in the cell membrane, and the larger section makes the cells more vulnerable to dialysis. This hypothesis would also explain the lower success rate in recording from smaller VD4 neurons $(\sim 35 \mu \mathrm{m}$ diameter) compared to LPeD1 $(50-100 \mu \mathrm{m})$ in PI chips. This issue is being addressed by patterning circular $2 \mu \mathrm{m}$ diameter apertures in recent PI chip designs. To delay the onset of dialysis, entry into the whole-cell configuration should be postponed (see below).

(2) Bath and subterranean channel ("pipette") solutions. Gigaseal formation was dependent upon the use of microfluidic solution ( $\mu \mathrm{FS}$; in $\mathrm{mM}$ : $50 \mathrm{KCl}, 5 \mathrm{MgCl}_{2}, 5 \mathrm{EGTA}$, and 5 HEPES; pH 7.4; 130 mOsm), in the subterranean channel, and consistently occurred spontaneously. Indeed, absence of cellattached or whole-cell configuration was observed when using conditioned medium (CM: isolated snail brains incubated in defined media for 3-4 days) in the subterranean microfluidics (Martina et al., 2011). We speculate that this phenomenon is related to microscale changes in osmotic pressure at the membrane patch, due to the ionic composition of the $\mu \mathrm{FS}$ $\left(\mathrm{K}^{+} 50 \mathrm{mM}\right.$ ), even though the bath (in $\mathrm{mM}: 51.3 \mathrm{NaCl}, 1.7$ 

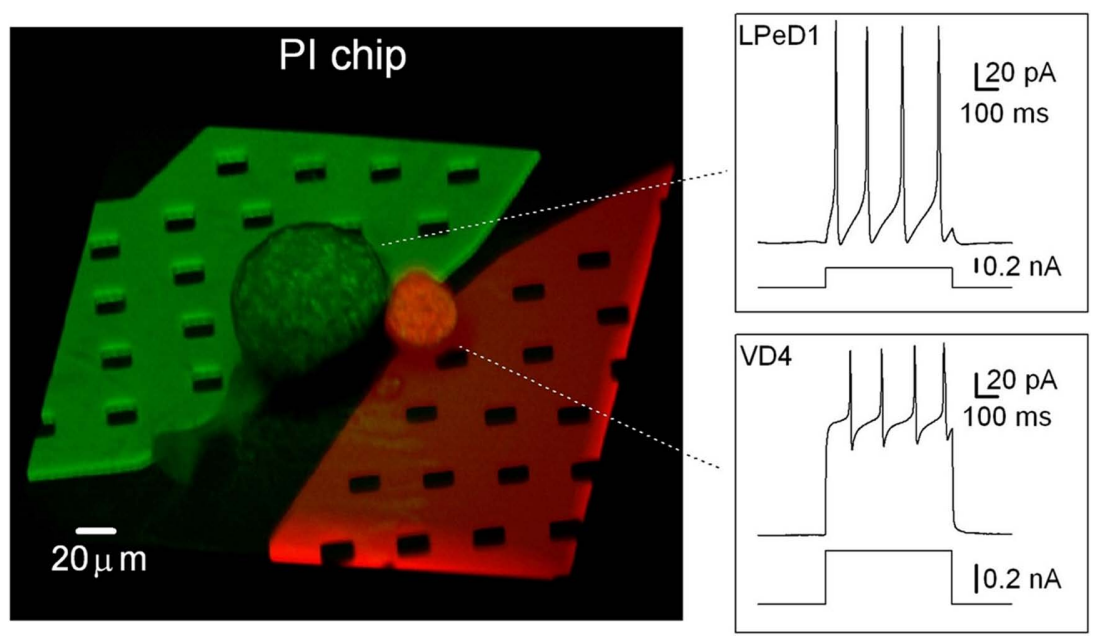

FIGURE 9 | Projection of a confocal 3-D reconstruction of a PI chip with a VD4 (red) and an LPeD1 (green) neuron, each plated over one aperture.

The LPeD1 subterranean microfluidic channel was filled with a recording solution containing Lucifer Yellow (green) while the VD4 channel was filled with a recording solution containing Texas-red (red). Insets show the simultaneous recording of the voltage responses to current injections for a VD4 and an LPeD1 neuron plated on the same PI chip. From Martina et al. (2011).

Table 1 | Summary of the experiments performed with Si and PI planar patch-clamp chips.

\begin{tabular}{|c|c|c|c|c|c|c|c|c|}
\hline & Cell & $n$ & C-A & C-A to W-C & Tot W-C & Tot success & Bad cells & Bad ephys \\
\hline \multirow[t]{2}{*}{ Si chip } & LPeD1 & 58 & $9(19 \%)$ & $5(56 \%)$ & $28(48 \%)$ & $32(55 \%)$ & $14(24 \%)$ & $12(21 \%)$ \\
\hline & VD4 & 26 & $4(15 \%)$ & $2(50 \%)$ & $15(58 \%)$ & $17(65 \%)$ & $2(8 \%)$ & $7(27 \%)$ \\
\hline \multirow[t]{2}{*}{ PI chip } & LPeD1 & 63 & $7(11 \%)$ & $5(71 \%)$ & $25(40 \%)$ & $27(43 \%)$ & 0 & $36(57 \%)$ \\
\hline & VD4 & 51 & $1(2 \%)$ & $1(100 \%)$ & $13(25 \%)$ & $13(25 \%)$ & $5(10 \%)$ & $33(65 \%)$ \\
\hline
\end{tabular}

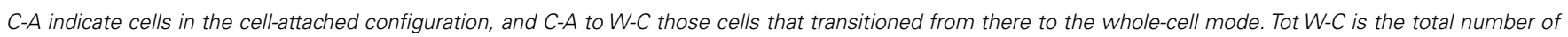

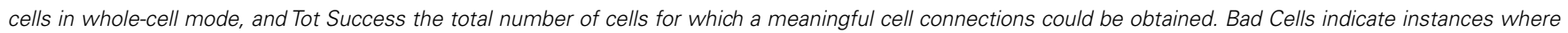

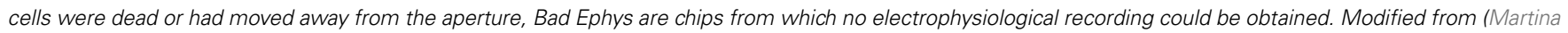
et al., 2011)

$\mathrm{KCl}, 4 \mathrm{CaCl}_{2}$, and $1.5 \mathrm{MgCl}_{2}$; buffered to $\mathrm{pH} 7.9$ with HEPES) and subterranean channel solutions were iso-osmotic. This may also account for the frequently observed spontaneous entry into the whole-cell configuration. It would be advantageous to promote giga-seal formation early, and delay entry into the whole-cell configuration by culturing neurons with $\mathrm{CM}$ instead of $\mu \mathrm{FS}$ in the fluidics, thereby allowing long-term cell-attached recording of ion channel activity.

(3) Cell preparation. Molluscan neurons are large, relatively robust and maintain their intrinsic and synaptic properties in cell culture (see Cell preparation). The next step in the development of this technology is the use of mammalian neurons. It is difficult to predict how mammalian cells will interact with the aperture features and surfaces on these chips. This is the subject of an ongoing study and encouraging preliminary results using primary cortical cultures from rats have, however, been reported (Martinez et al., 2010a). In addition the success rates were similar when snail neurons were cultured for $2-4$ or $8-12 \mathrm{~h}$ suggesting that the time in culture does not affect successful whole-cell entry.

\section{CELL PLACEMENT}

The snail neurons used to validate our technology are large enough that they can be manually positioned on the aperture. This method however requires high technical skills, just like glass pipette patchclamping, and many smaller cells will not be amenable to it. Current automated patch-clamp systems, working from suspensions, aspirate the cell in place (Fluxion ${ }^{7}$; Molecular-Devices ${ }^{8}$; Nanion ${ }^{9}$; Sophion ${ }^{10}$ ). Cultured neurons, however, offer a biological model that is substantially more relevant for experimentation, notably for network communication. However, since cultures are typically too sparse to rely on chance for a cell to be positioned on the aperture, specific strategies for positioning the cells are needed. While topographical features have been shown to restrict cells and guide the growth of processes (Faid et al., 2005; Merz and Fromherz, 2005; Sorkin et al., 2009), chemical patterning is by far the favored

\footnotetext{
${ }^{7}$ http://fluxionbio.com/

${ }^{8} \mathrm{http}: / /$ www.moleculardevices.com

${ }^{9}$ http://www.nanion.de/

${ }^{10} \mathrm{http}: / /$ www.sophion.dk/
} 
method (Wheeler and Brewer, 2010). Chemical modification can be used not only to immobilize cells on the aperture, but also to promote the formation of a high quality cell to aperture seal. We have studied several strategies to position cells on the apertures, and report here the aligned stamping of polylysine on our apertures. We improve on that process by using standard lithography for alignment and replacing physisorption by chemisorption.

\section{STAMPING}

Micro-contact printing, or PDMS stamping, has been demonstrated to result in the transfer of chemicals with high spatial resolution (Kumar et al., 1994; Qin et al., 2010) and to result in cell placement (Wheeler et al., 1999; Wyart et al., 2002; Vogt et al., 2005; Charrier et al., 2006; Offenhausser et al., 2007). In order to induce placement of neurons on our chips, Poly-D-lysine (PDL) patterns were stamped (Charrier et al., 2010). PDL is a commonly used cell attachment factor (Branch et al., 1998; Chang et al., 2003; $\mathrm{Li}$ and Folch, 2005) and cultured cryopreserved rat cortical cells (QBM Cell Sciences, Ottawa, ON, Canada) adhere well to PDL.

PDMS stamps were designed with square features of sizes and spacings of 25,50 , and $100 \mu \mathrm{m}$ to determine optimal conditions for placement (Charrier et al., 2010). Fabrication was done by replicamolding from a SU8-on-Si master mold, using the same polymer as for the microchannels in PI chips. To remove any remaining non-polymerized PDMS, stamps were washed in solvents by reflux following an established procedure (Voicu et al., 2007). Stamps were mounted on glass slides, washed in $70 \%$ ethanol, deionized (DI) water, and 10\% Sodium Dodecyl Sulfate (SDS). Modification of the PDMS surface with SDS has been shown to enhance the transfer of polylysine to the substrate (Chang et al., 2003). Stamps were quickly rinsed in DI water, blow-dried with nitrogen, immersed for $30 \mathrm{~min}$ in a PDL saline solution $(33 \mathrm{mg} / \mathrm{mL}$ PDL in standard PBS) then thoroughly blow-dried. Stamps (surface area approximately $0.5 \mathrm{~cm}^{2}$ ) were applied to chips with a constant and homogeneous pressure of $500 \mathrm{~g}$ for $1 \mathrm{~min}$ and left another minute without pressure. The chips were finally sterilized $2 \mathrm{~min}$ in $70 \%$ ethanol, rinsed in DI water and dried.

Cryopreserved rat cortical cells were thawed in a $37^{\circ} \mathrm{C}$ water bath, resuspended in media and plated on stamped chips. Four hours post-plating, media was removed and replaced with $1 \mathrm{~mL}$ of serum-free Neurobasal Medium. Media changes were performed biweekly by replacing half of the media with fresh Neurobasal Medium. Cell cultures were maintained at $37^{\circ} \mathrm{C}$ in a $5 \% \mathrm{CO}_{2}$ humidified incubator for 14 days before imaging. The cells have a body diameter of $10-12 \mu \mathrm{m}$, and the size of the PDL-patterned areas will influence the number of neurons that will adhere and grow on individual squares. We found by fluorescence imaging studies that $100 \mu \mathrm{m}$ PDL squares were covered with $10 \pm 3$ cells $(n=25), 50 \mu \mathrm{m}$ squares had $3 \pm 2$ cells $(n=60)$, and $25 \mu \mathrm{m}$ squares $1 \pm 1$ ( $n=60,50 \%$ vacant). In cases where the number of neurons per PDL area exceeded 12, large three dimensional aggregates formed, covering most of the patterned area. Based on these observations, we selected the $50 \mu \mathrm{m}$ patterns to investigate further. Immunostaining was used to confirm the identity of neurons (MAP2-red) and astrocytes (GFAP-green) growing on the chips. Cultures were fixed, incubated overnight at $4^{\circ} \mathrm{C}$ in Mouse monoclonal Map2 antibody and goat anti-rabbit GFAP antibody, rinsed in PBS, incubated in secondary antibodies Alexa Fluor 568 goat anti-mouse and Alexa Fluor 488 goat anti-rabbit for $1 \mathrm{~h}$ at room temperature, and samples inverted onto coverslips containing a drop of fluorescent mounting medium.

As seen in Figure 10, processes extended between small groups of neurons isolated on $50 \mu \mathrm{m}$ squares to proximal populations of neurons on neighboring squares, such that $3 \pm 1$ extended from each neuronal subpopulation $(n=25)$. It can be seen that processes extend preferentially, though not exclusively, to immediate neighboring squares. Stamps with $50 \mu \mathrm{m}$ squares patterns were then aligned to the apertures of a patch-clamp chip using a chip bonder and stamped with a force of $500 \mathrm{~g}$ applied for $60 \mathrm{~s}$. Figure 11 shows images of neurons growing on this region of the substrate after 14 days in vitro. The image is a superimposition of reflection and fluorescence images. A slight shift of the pattern occurred while stamping on the lower aperture region, probably due to deformation of the PDMS stamp while applying pressure. However, the upper aperture region is covered with cells and a neuron is growing directly over the aperture.

\section{CHEMISORPTION AND LITHOGRAPHY}

While Figures 10 and 11 clearly demonstrate cell placement on patch-clamp chips, the stamping method is not commensurate with manufacturing. Soft PDMS stamps tend to collapse where protruding features, bearing the patterns to be printed, are separated by distances large in comparison with the height of the features. Furthermore, precise alignment of the stamp to the

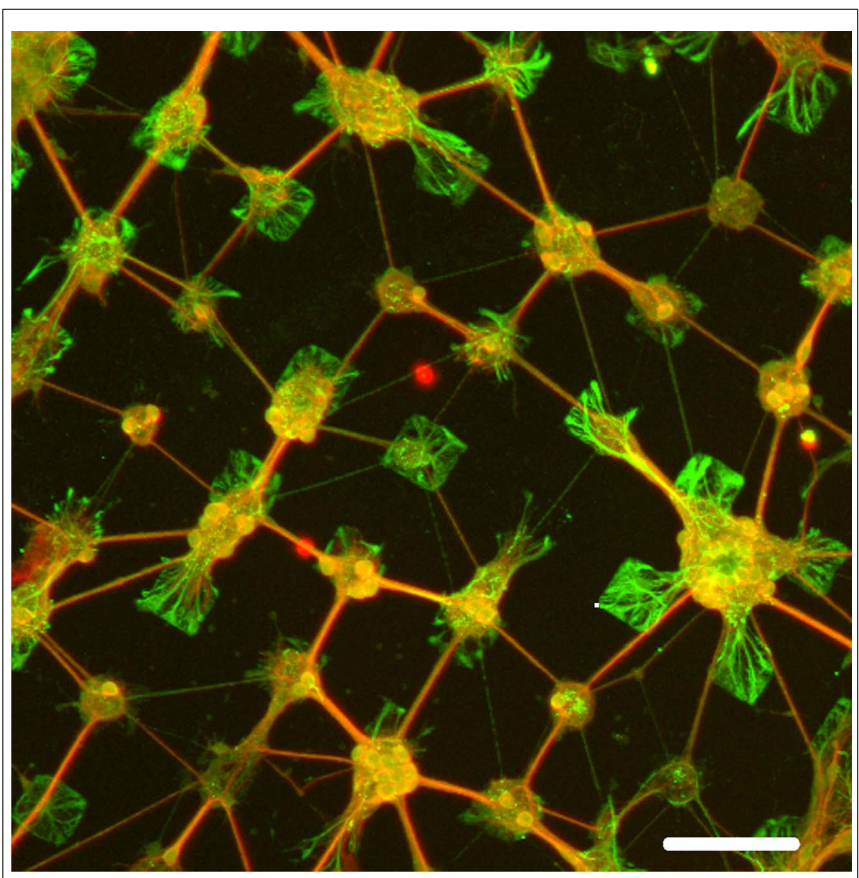

FIGURE 10 | Immunofluorescence staining of cultured brain cells on chips stamped with $\mathbf{5 0} \mu \mathrm{m}$ PDL pattern spaced by $\mathbf{5 0} \boldsymbol{\mu} \mathbf{m}$ separation. Neurons are stained red with MAP2, while astrocytes are stained green with GFAP. Note the processes that extend mostly immediately neighboring squares. Scale bar: $100 \mu \mathrm{m}$. From Charrier et al. (2010). 
patch-clamp array chip is a low-yield process and complicated by distortions and defects in planarization. An alternate process based on standard lithography was developed, and derivatization of the $\mathrm{SiO}_{2}$ surface of the $\mathrm{Si}$ chips was designed to provide a generalized chemical bonding attachment method rather than rely on physisorption, which may be too weak or unstable for some cell attachment factors (Diaz-Quijada et al., 2011).

The derivatization process is described in Figure 12A. $\mathrm{Si}$ chips were piranha cleaned $\left[\mathrm{H}_{2} \mathrm{SO}_{4}: \mathrm{H}_{2} \mathrm{O}_{2} \quad(3: 1)\right]$ and reacted with aminopropyltriethoxysilane (APTES) to obtain an amine-terminated surface. It was then reacted with buffered poly(methacrylic acid) in the presence $\mathrm{N}$-(3-dimethylaminopropyl)- $N^{\prime}$-ethylcarbodiimide hydrochloride (EDC) and $N=$ hydroxysuccinimide (NHS), resulting in a carboxylic acid-terminated surface (Diaz-Quijada et al., 2007). The substrates were then washed, dried, activated in the presence of NHS and EDC before the immobilization of a cell adhesion promoter such as PDL. The carboxylic acid-terminated surfaces are highly versatile as they can be activated and made reactive toward a variety

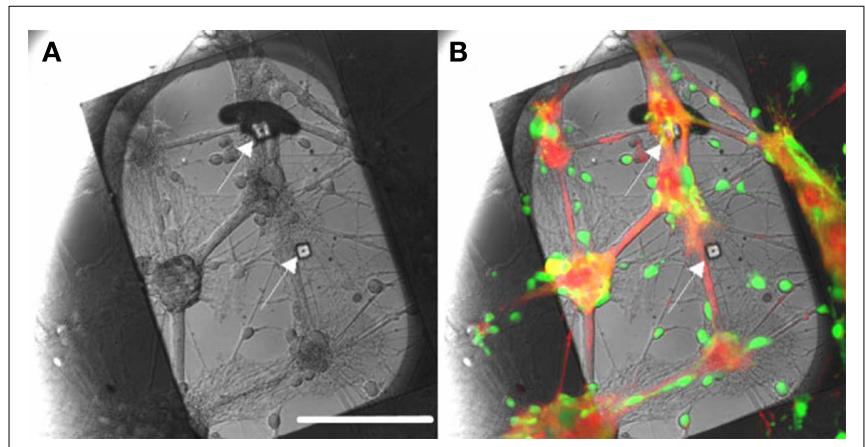

FIGURE 11 | Patch-clamp chip with two apertures (100 $\mu \mathrm{m}$ apart), stamped with $\mathbf{5 0} \boldsymbol{\mu} \mathbf{m}$ PDL squares. Note that subterranean microfluidic channels are not visible here. The stamp was aligned with the apertures using an aligner-bonder and stamped with a 500-g force for $1 \mathrm{~min}$. After 14 days in vitro, cells bodies were labeled with Calcein-AM (green) and membranes with WGA conjugate (red). (A) Reflection image: apertures are indicated by arrows. (B) Superimposition of the images obtained in reflection mode and fluorescence. A neuron is positioned over the upper aperture. Scale bar: $100 \mu \mathrm{m}$. From Charrier et al. (2010).

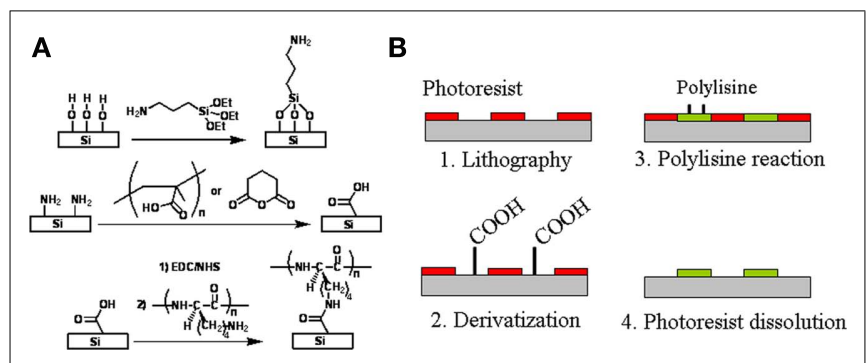

FIGURE 12 | Chemical patterning of polylysine squares. (A) Surface derivatization to successively obtain amino- and carboxylic acid-terminated surfaces on which a polylysine peptide is chemically bonded. (B) Chemical patterning is obtained by lithographically defining openings in a photoresist, derivatizing the surface, reacting it to polylysine in the presence of EDC and NHS and dissolving the photoresist. Adapted from Diaz-Quijada et al. (2011). of amine rich biomolecules (such as proteins) or cell adhesion promoters. Polymers and large biomolecules such as proteins can physisorb on surfaces, as it is the case for Bovine Serum Albumin (Zhao et al., 2007; Milligan et al., 2009; Ogi et al., 2009), due to ionic, dipole, and Van der Waals interactions between molecules and surfaces. Consequently, it is traditional to simply physisorb polylysine on surfaces such as $\mathrm{SiO}_{2}$ or glass (Pleasure et al., 1981; Feldner et al., 1983). Such modifications are however not stable over time in environments of high ionic strength. A comparative study of physisorbed and chemisorbed PDL indicates that in the physisorbed case PDL not only smears out during washing with PBS buffer but also yields a lower surface density than in the chemically immobilized case. It is also important to note that physisorption is not a viable method for the modification of surfaces with small molecules. This is illustrated in our study (Diaz-Quijada et al., 2011) with short peptide sequences cyclo(RGDFK-PEG) peptide (PCI-3696-PI), which induces cell adhesion via a molecular recognition event (Ruoslahti and Pierchbacker, 1986), and cyclo(RADFK-PEG) (PCI-3954-PI), which differs by only one amino acid and does not induce cell adhesion. Cultured cells attach on chemisorbed PCI-3696-PI with high density, but are not viable on either physisorbed PCI-3696-PI or chemisorbed PCI-3954-PI.

As shown in Figure 12B, chemical patterning of PDL was accomplished by defining square openings in a photosensitive resin, derivatizing the surface as illustrated in Figure 12A, reacting the surface to PDL in the presence of EDC and NHS and finally dissolving the photoresist in acetone. Photolithography has been demonstrated as a potential technique for chemical patterning of surfaces (Lom et al., 1993; Butler et al., 2006; Falconnet et al., 2006). Our strategy for the chemical immobilization of cell adhesion promoters was modified and optimized to be compatible with common photoresists, which would swell or dissolve in polar organic solvents. The preparation of carboxylic acid surfaces was performed with poly(acrylic acid) instead of glutaric anhydride. This polymeric reagent has the advantage of not only producing a high concentration of carboxylic acid groups, but also allows the reaction with the amino terminated surfaces to be carried out in aqueous media in the presence of EDC and NHS. Efficient modification of the exposed regions of $\mathrm{SiO}_{2}$ require clean surfaces, free from residual photoresist or any other substances that may mask the surface and prevent the reaction with silane reagents. Consequently, conventional photoresist adhesion promoters were avoided, all samples were over developed and then cleaned in an air plasma. To facilitate photoresist adhesion, wafers were instead dehydrated at $105^{\circ} \mathrm{C}$ prior to spin-coating (Madou, 1997); an alternative approach, which proved to have a higher success rate, was based on amino modification of the chips. Undesirable crosslinking effects were observed in the photoresist, resulting in difficulties with the photoresist dissolution step. The effect is likely due to the generation of hydroxyl and carboxylic acid groups in the photoresist which can react with each other to form ester groups in the presence of EDC and NHS. These groups are formed during the plasma cleaning performed immediately prior to silanization, which had to be kept to a minimum. In addition to the above key points, we observed that the reaction of APTES with the photoresist patterned $\mathrm{SiO}_{2}$ surface had to be limited to $4 \mathrm{~h}$ in the gas phase to prevent swelling and detachment of the photoresist. 
To illustrate the concept with our chemical strategy, blank Si chips were photolithographically patterned with $100 \mu \mathrm{m}$ squares with a pitch of 200 or $400 \mu \mathrm{m}$. Alexafluor 555 modified PDL was chemically immobilized on the patterned surface in the presence of NHS and EDC. Fluorescent imaging of the chemically patterned surface is presented in Figure 13. Cryopreserved rat cortical neurons were cultured as described in 4.1 for 14-19 days on a wafer patterned with unlabeled PDL. Staining of the cells with Calcein (green) for cell viability and RH-237 (red) for cell membranes allow the visualization of the patterned cells along with their processes.

\section{CONCLUSION}

A silicon patch-clamp chip with an optimized aperture shape to facilitate the formation of seals has been designed, fabricated, and successfully tested (Py et al., 2010). It is fabricated on 6" wafers in a commercial-grade prototyping foundry with nearperfect yield, and is highly manufacturable. A novel polyimidesilicone (PI-PDMS) hybrid chip (Martinez et al., 2010b) which may simultaneously monitor several neurons engaged in network communication at the resolution of the patch-clamp technique (Mealing et al., 2005a,b), has also been reduced to practice (Martina et al., 2011). While their shunt capacitance are still somewhat higher than what is attainable with glass pipettes (Hamill et al., 1981), the access resistance of those two patch-clamp chips is very low and the quality of traces they can record is high (Figure 6).

Fifty-eight percentage of meaningful cell to aperture connections were observed with Si chips and 35\% with PI chips. These success rates are lower than the best values reported for cells from suspensions (Milligan et al., 2009; Nagarah et al., 2010), but high enough to validate this technology. The optimization of the aperture size and shape, and the perfusion of different solutions in the subterranean channels to control giga-seals and whole-cell entry are the parameters at play in the formation of seals, and must be optimized in further studies to bring up the success rates. The capacity of both Si and PI chips to allow cytoplasmic perfusion via subterranean microfluidics without disruption of recording has been shown; it could be used in disease models or pharmaceutical studies alike in order to modify the fate of individual cells within a functioning network. The ability to keep the cells in the whole-cell mode for several hours affords the possibility of studying longterm effects and as such is of value to secondary drug screening. While the challenges of applying this technology to mammalian cells should not be underestimated, preliminary whole-cell patchclamp recordings from rat cortical cultures (Martinez et al., 2010a) suggest that this is an achievable goal well worth pursuing. It is also important to recognize the potential for application of multipleaperture patch-clamp array chips to other biological disciplines where high-resolution assessment of cell-to-cell communication is required, including cardiology (Witchel, 2010).

The simultaneous recording of the activity of multiple cultured cells requires chemical patterning to promote their placement on the apertures. A proof-of-concept method that effectively brings cells over the apertures has been reported (Charrier et al., 2010) and the polypeptide stamping technique has been refined for a manufacturable process that provides stable chemical bonds (Diaz-Quijada et al., 2011). While the polylysine attachment factor we used in our experiments provides satisfactory placement when simply physisorbed, short peptide sequences such as RGD and RAD would not adhere. We also suggest that cell placement allows the synthesis of organized networks where processes are controlled between immediate neighbors. Organized network with neurons
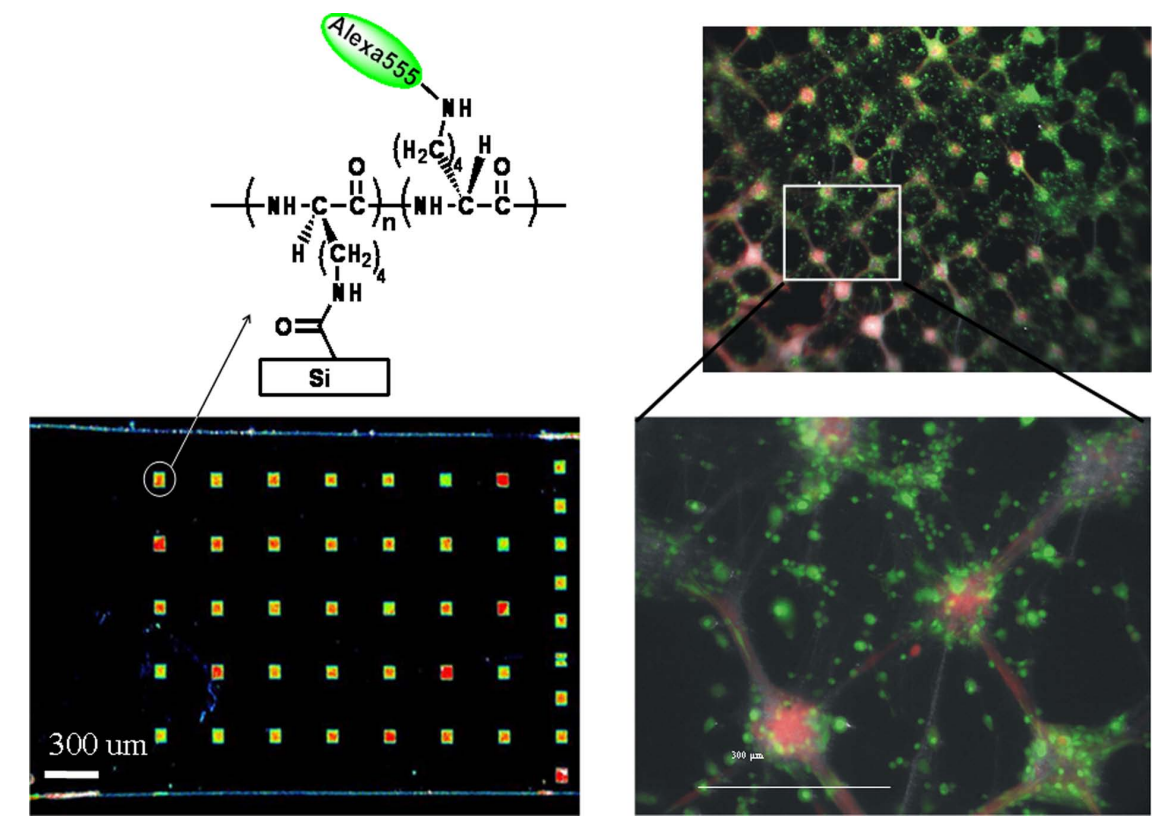

FIGURE 13 | Proof-of-concept demonstration of chemical patterning of fluorescently labeled polylysine (left) using conventional photolithography, followed by culture of cryopreserved rat cortical neurons (right). Cells were visualized by staining with $\mathrm{Calcein}$ (viability) and $\mathrm{RH}-237$ (membrane) dyes. Adapted from Diaz-Quijada et al. (2011). 
aligned on apertures will facilitate the analysis and modeling of brain connectivity, which determines functionality in neuronal circuits (Honey et al., 2010).

Many of the patch-clamp chip developments reported to date make it possible, or actually demonstrate, the integration of multiple patches on-chip (see part 2 for references). The application of those multiple patches on-chip are either to conduct parallel measurements that increase throughput in drug screening [Molecular-Devices (see footnote 8); Nanion ${ }^{11}$; Sophion (see footnote 10); Kiss et al., 2003; Bruggemann et al., 2006], or to obtain population recordings [Fluxion (see footnote 7); IonescuZanetti et al., 2005]. However, to our knowledge, only one other team has reported an attempt to monitor the activity of networks with the patch-clamp method (Alberti et al., 2010). We have reported the first application of a planar patch-clamp technology to examine neuronal synaptic communication. Positioning preand post-synaptic Lymnaea neurons in close proximity allowed functional synapses to establish in culture on the chip substrate. Data acquired with the Si and PI chips from neurons organized in this elementary network were used to describe network properties and demonstrate the suitability of our chip designs for synaptically connected neurons. Action potentials were evoked in LPeD1 and VD4 neurons. Functionality and nature of these VD4/LPeD1 neuron synapses were demonstrated by direct recordings and pharmacologically testing post-synaptic responses from LPeD1 on-chip. Importantly, a transient increase in the amplitude of spontaneous

${ }^{11} \mathrm{http}: / / w w w . n a n i o n . d e /$ products/syncropatch-96.html.

\section{REFERENCES}

Alberti, M., Snakenborg, D., Lopacinska, J. M., Dufva, M., and Kutter, J. P. (2010). Characterization of a patch-clamp microchannel array towards neuronal networks analysis. Microfluid. Nanofluidics 9, 963-972.

Allenby, G., Dodgson, K., Harper, P., Kassam, A., Leam, M., Dale, I., and Sullivan, E. (2001). Automated high throughput screening of fluorescent imaging plate reader (FLIPR) assays using assay platform ${ }^{\mathrm{TM}}$ integrated with activity base for 'on the fly' compound reconfirmation. J. Assoc. Lab. Autom. 6, 48-50.

Aziz, J. N. Y., Genov, R., Bardakjian, B. L., Derchansky, M., and Carlen, P. L. (2007). Brain-silicon interface for high-resolution in-vitro neural recording. IEEE Trans. Biomed. Circuits Syst. 1, 56-62.

Behrends, J. C., and Fertig, N. (2007). "Planar patch-clamp," in PatchClamp Analysis: Advanced Techniques, Chapt. 14, 2nd Edn. ed. W. Walz (Secaucus, NJ: Springer Protocols), 411-433.

Bell, H. J., and Syed, N. I. (2009). Hypoxia-induced modulation of the

events (synaptic potentiation) following a short burst of action potentials in the pre-synaptic cell was recorded on-chip.

The polyimide-silicone chip is readily scalable to multiple recording sites. Practical limitations imposed by the subterranean microfluidic channels, such as space and chip-to-world interfacing, would require a different design to expand beyond eight apertures. However, for many assessment studies it is of greater importance to be able to patch-clamp several connected neurons than it is to monitor extracellular field potentials from hundreds or thousands of neurons. Simultaneous pre- and post-synaptic recordings on a patch-clamp chip have tremendous value as a model to investigate synaptic function and for use as an assay to advance drug development. Furthermore, fundamental aspects of complex network activity, resulting in specific functions such as the acquisition of memory, can be reduced to modeling and studying interactions between just three neurons (Lukowiak and Syed, 1999; Milo et al., 2002; Song et al., 2005). This makes the application of multiple-aperture patch-clamp array chips to cultures of communicating neurons an important and promising technology to advance functional assay development.

\section{ACKNOWLEDGMENTS}

The authors wish to thank Alexei Bogdanov, Simon Wingar, Juan Caballero, and the CPFC team for fabrication of the Si chips, Hue Tran and Allan Horner for packaging, Jeff Fraser for SEM imaging, Mark Malloy, Raluca Movileanu, and Christy Maynard for chip functionalization, and Walli Zaidi for the preparation of cultured neurons. This work was supported in part by a CIHR grant to NIS. Collin Luk is supported by AIHS and NSERC studentship awards.

Mealing, G. (2010). Cell placement and guidance on substrates for neurochip interfaces. Biotechnol. Bioeng. 105, 368-373.

Charrier, A., Porri, T. J., Murphy, C. J., and Nealey, P. F. (2006). A new method to characterize chemically and topographically nanopatterned surfaces. J. Biotechnol. 126, 196-204.

Chen, C., and Folch, A. (2006). A high-performance elastomeric patch clamp chip. Lab Chip 6, 1338-1345.

Chen, C.-Y., Tu, T.-Y., Chen, C.-H., Jong, D.-S., and Wo, A. M. (2009). Patch clamping on plane glass - fabrication of hourglass aperture and highyield ion channel recording. Lab Chip 9, 2370-2380.

Chen, C.-Y., Tu, T.-Y., Jong, D.-S., and Wo, A. M. (2011). Ion channel electrophysiology via integrated planar patch-clamp chip with on-demand drug exchange. Biotechnol. Bioeng. 108, 1395-1403.

Conte Camerino, D., Tricarico, D., and Desaphy, J. -F. (2007). Ion channel pharmacology. Neurotherapeutics 4, 184-198.

Craig, A., Graf, E., and Linhoff, M. (2006). How to build a central synapse: clues from cell culture. Trends Neurosci. 29, 8-20.

Curtis, J. C., Baldwin, K., Dworak, B. J., Stevenson, T. J. M., Delivopoulos, E., MacLeod, N. K., and Murray, A. F. (2008). Seal formation in silicon planar patch-clamp microstructures. J. Microelectromech. Syst. 17, 974-983.

Dan, Y., and Poo, M. (2004). Spike timing-dependent plasticity of neural circuits. Neuron 44, 23-30.

Diaz-Quijada, G., Maynard, C., Comas, T., Monette, R., Py, C., Krantis, A., and Mealing, G. (2011). Surface patterning with chemisorbed chemical cues for advancing neurochip applications. Ind. Eng. Chem. Res. 50, 10029-10035.

Diaz-Quijada, G. A., Peytavi, R., Nantel, A., Roy, E., Bergeron, M. G., Dumoulin, M. M., and Veres, T. (2007). Surface modification of thermoplastics-towards the plastic biochip for high throughput screening devices. Lab Chip 7, 856-862.

Dunlop, J., Bowlby, M., Peri, R., Vasilyev, D., and Arias, R. (2008). Highthroughput electrophysiology: an emerging paradigm for ion-channel 
screening and physiology. Nat. Rev. Drug Discov. 7, 358-368.

Egert, U., Okujeni, S., Nisch, W., Stett, A., Boven, K. -H., Rudorf, R., and Gottschlich, N. (2005). Perforated Microelectrode Arrays Optimize Oxygen Availability and Signal-toNoise Ratio in Brain Slice Recordings. Freiburg: Micro System Technic Kongress.

Faid, K., Voicu, R., Bani-Yaghoub, M., Tremblay, R., Mealing, G., Py, C., and Barjovanu, R. (2005). Rapid fabrication and chemical patterning of polymer microstructures and their applications as a platform for cell cultures. Biomed. Microdevices 7, 179-184.

Falconnet, D., Csucs, G., Grandin, H. M., and Textor, M. (2006). Surface engineering approaches to micropattern surfaces for cell-based assays. Biomaterials 27, 3044-3063.

Feldner, J., Bredt, W., and Kahane, I. (1983). Influence of cell shape and surface charge on attachment of Mycoplasma pneumoniae to glass surfaces. J. Bacteriol. 153, 1-5.

Feng, Z., Klumperman, J., Lukowiak, K., and Syed, N. (1997). In vitro synaptogenesis between the somata of identified Lymnaea neurons requires protein synthesis but not extrinsic growth factors or substrate adhesion molecules. J. Neurosci. 17, 7839-7849.

Fertig, N., George, M., Klau, M., Meyer, C., Tilke, A., Sobotta, C., Blick, R. H., and Behrends, J. C. (2003). Microstructured apertures in planar glass substrates for ion channel research. Recept. Channels 9, 29-40.

Fertig, N., Meyer, C., Blick, R. H., Trautmann, C., and Behrends, J. C. (2001). Microstructured glass chip for ion-channel electrophysiology. Phys. Rev. E 64, 040901 (R).

Fertig, N., Tilke, A., Blick, R. H., Kotthaus, J. P., Behrends, J. C., and Bruggencate, G. t. (2000). Stable integration of isolated cell membrane patches in a nanomachined aperture. Appl. Phys. Lett. 77, 1218-1220.

Frey, U., Egert, U., Heer, F., Hafizovic, S., and Hierlemann, A. (2009). Microelectronic system for highresolution mapping of extracellular electric fields applied to brain slices. Biosens. Bioelectron. 24, 2191-2198.

Fromherz, P. (2003). "Neuroelectronic Interfacing: semiconductor chips with ion channels, brain cells, and nerves," in Nanoelectronics and Information Technology, Chapt. 32, ed. R. Waser (Berlin: Wiley), 781-810.

Fromherz, P., Offenhausser, A., Vetter, T., and Weis, J. (1991). A neuron- silicon junction - a Retzius cell of the leech on an insulated-gate field-effect transistor. Science 252, 1290-1293.

Gad-el-Hak, M. (2001). The MEMS Handbook. New York, NY: CRC Press.

Graham, A. H. D., Robbins, J., Bowen, C. R., and Taylor, J. (2011). Commercialisation of CMOS integrated circuit technology in multielectrode arrays for neuroscience and cell-based biosensors. Sensors 11, 4943-4971.

Hai, A., Shappir, J., and Spira, M. E. (2010). In-cell recordings by extracellular microelectrodes. Nat. Methods 7, 200-202.

Hamakawa, T., Woodin, M. A., Bjorgum, M. C., Painter, S. D., Takasaki, M., Lukowiak, K., Nagle, G. T., and Syed, N. I. (1999). Excitatory synaptogenesis between identified Lymnaea neurons requires extrinsic trophic factors and is mediated by receptor tyrosine kinases. J. Neurosci. 19, 9306-9312.

Hamblin, M. N., Edwards, J. M., Lee, M. L., Woolley, A. T., and Hawkins, A. R. (2007). Electroosmotic flow in vapor deposited silicon dioxide and nitride microchannels. Biomicrofluidics 1, 034101.

Hamill, O. P., Marty, A., Neher, E., Sakmann, B., and Sigworth, F. J. (1981). Improved patch-clamp techniques for high-resolution current recording from cells and cell-free membrane patches. Pflügers Arch. 391, 85-100.

Hediger, S., Sayah, A., and Gijs, M. A. M. (1999). Fabrication of a novel microsystem for the electrical characterisation of cell arrays. Sens. Actuators B Chem. 56, 175-180.

Honey, C. J., Thivierge, J. P., and Sporns, O. (2010). Can structure predict function in the human brain? Neuroimage 52, 766-776.

Huys, R., Braeken, D., Van Meerbergen, B., Winters, K., Eberle, W., Loo, J., Tsvetanova, D., Chen, C., Severi, S., Yitzchaik, S., Spira, M., Shappir, J., Callewaert, G., Borghs, G., and Bartic, C. (2008). Novel concepts for improved communication between nerve cells and silicon electronic devices. Solid State Electron. 52, 533-539.

Ionescu-Zanetti, C., Shaw, R. M., Seo, J., Jan, Y. -N., Jan, L. Y., and Lee, L. P. (2005). Mammalian electrophysiology on a microfluidic platform. Proc. Natl. Acad. Sci. U.S.A. 102, 9112-9117.

Jones, I. L., Livi, P., Lewandowska, M. K., Fiscella, M., Roscic, B., and Hierlemann, A. (2011). The potential of microelectrode arrays and microelectronics for biomedical research and diagnostics. Anal. Bioanal. Chem. 399, 2313-2329.

Katz, L., and Shatz, C. (1996). Synaptic activity and the construction of cortical circuits. Science 274, 1133-1138.

Kaul, A. R., Syed, N. I., and Fromherz, P. (2004). Neuron-semiconductor chip with chemical synapse between identified neurons. Phys. Rev. Lett. 92, 381021-381024.

Kiss, L., Bennett, P. B., Uebele, V. N., Koblan, K. S., Kane, S. A., Neagle, B., and Schroeder, K. (2003). High throughput ion-channel pharmacology: planar-array-based voltage clamp. Assay Drug Dev. Technol. 1(Suppl. 2), 127-135.

Klemic, K. G., Klemic, J. F., Reed, M. A., and Sigworth, F. J. (2002). Micromolded PDMS planar electrode allows patch clamp electrical recordings from cells. Biosens. Bioelectron. 17, 597-604.

Klemic, K. G., Klemic, J. F., and Sigworth, F. J. (2005). An air-molding technique for fabricating PDMS planar patch-clamp electrodes. Pflüger Arch. 449, 564-572.

Kumar, A., Biebuyck, H. A., and Whitesides, G. M. (1994). Patterning selfassembled monolayers - applications in materials science. Langmuir 10, 1498-1511.

Lambacher, A., Jenkner, M., Merz, M., Eversmann, B., Kaul, R. A., Hofmann, F., Thewes, R., and Fromherz, P. (2004). Electrical imaging of neuronal activity by multitransistor-array (MTA) recording at $7.8 \mathrm{mu} \mathrm{m}$ resolution. Appl. Phys. A Mater. Sci. Process. 79, 1607-1611.

Lau, A., Hung, P., Wu, A., and Lee, L. (2006). Open-access microfluidic patch-clamp array with raised lateral cell trapping sites. Lab Chip 6, 1510-1515.

Lehnert, T., Gijs, M. A. M., Netzer, R., Bischoff, U., and Evotec Oai Ag/Genion, D. H. (2002). Realization of hollow $\mathrm{SiO}_{2}$ micronozzles for electrical measurements on living cells. Appl. Phys. Lett. 81, 5063-5065.

Lehnert, T., Nguyen, D., Baldi, L., and Gijs, M. (2007). Glass reflow on 3-dimensional micro-apertures for electrophysiological measurements on-chip. Microfluid. Nanofluidics 3 , 109-117.

Li, N. Z., and Folch, A. (2005). Integration of topographical and biochemical cues by axons during growth on microfabricated 3-D substrates. Exp. Cell Res. 311, 307-316.

Li, X., Klemic, K. G., Reed, M. A., and Sigworth, F. J. (2006). Microfluidic system for planar patch clamp electrode arrays. Nano Lett. 6, 815-819.

Lom, B., Healy, K. E., and Hockberger, P. E. (1993). A versatile technique for patterning biomolecules onto glass coverslips. J. Neurosci. Methods 50, 385-397.

Luk, C., Naruo, H., Prince, D., Hassan, A., Doran, S., Goldberg, J., and Syed, N. (2011). A novel form of presynaptic CaMKII-dependent short-term potentiation between Lymnaea neurons. Eur. J. Neurosci. 34, 567-577.

Lukowiak, K., and Syed, N. I. (1999). Learning, memory and a respiratory central pattern generator. Comp. Biochem. Physiol. Mol. Integr. Physiol. 124, 265-274.

Madou, M. (1997). Fundamentals of Microfabrication. New York, NY: CRC Press LLC.

Martina, M., Luk, C., Py, C., Martinez D., Monette, R., Comas, T., Denhoff, M. W., Syed, N., and Mealing, G. A. R. (2011). Interrogation of cultured neurons using patch-clamp chips. J. Neural Eng. 8, 034002.

Martinez, D., Martina, M., Kremer, L., Monette, R., Comas, T., Salim, D. Py, C., Denhoff, M. W., and Mealing, G. (2010a). Development of patch-clamp chips for mammalian cell applications. Micro Nanosystems 2, 274-279

Martinez, D., Py, C., Denhoff, M., Martina, M., Monette, R., Comas, T., Luk, C., Syed, N., and Mealing, G. (2010b). High-fidelity patch-clamp recordings from neurons cultured on a polymer microchip. Biomed. Microdevices 12, 977.

Matthews, B., and Judy, J. W. (2006). Design and fabrication of a micromachined planar patch-clamp substrate with integrated microfluidics for single-cell measurements. $J$. Microelectromech. Syst. 15, 214-222.

MEA Meeting. (2010). "See for example papers within Neuronal dynamics and plasticity," in Proceedings of the 7th International Meeting on Susbtrate-integrated Microelectrode Arrays, June 29-July 2, Reutlingen.

Mealing, G., Bani-Yaghoub, M., Py, C., Voicu, R., Barjovanu, R., Tremblay, R., Monette, R., Mielke, J., and Faid, K. (2005a). "Application of polymer microstructures with controlled surface chemistries as a platform for creating and interfacing with synthetic neural networks," in International Joint Conference on Neural Networks 2005 Conference Proceedings, Montreal, CA, 3116-3120.

Mealing, G., Py, C., Denhoff, M., Dowlatshahi, R., Faid, K., Voicu, R., and Bani, M. (2005b). PCT patent application PCT/CA2005/000682. 
Merz, M., and Fromherz, P. (2005). Silicon chip interfaced with a geometrically defined net of snail neurons. Adv. Funct. Mater. 15, 739-744.

Metz, S., Holzer, R., and Renaud, P. (2001). Polyimide-based microfluidic devices. Lab Chip 1, 29-34.

Milligan, C. J., Li, J., Sukumar, P., Majeed, Y., Dallas, M. L., English, A., Emery, P., Porter, K. E., Smith, A. M., McFadzean, I., Beccano-Kelly, D., Bahnasi, Y., Cheong, A., Naylor, J., Zeng, F., Liu, X., Gamper, N., Jiang, L.-H., Pearson, H. A., Peers, C., Robertson, B., and Beech, D. J. (2009). Robotic multiwell planar patch-clamp for native and primary mammalian cells. Nat. Protoc. 4, 244-255.

Milo, R., Shen-Orr, S., Itzkovitz, S., Kashtan, N., Chklovskii, D., and Alon, U. (2002). Network motifs: simple building blocks of complex networks. Science 298, 824-827.

Morales, R., Riss, M., Wang, L., Gavín, R., Del Río, J. A., Alcubilla, R., and Claverol-Tinturé, E. (2008). Integrating multi-unit electrophysiology and plastic culture dishes for network neuroscience. Lab Chip 8, 1896-1905.

Nagarah, J. M., Paek, E., Luo, Y., Wang, P., Hwang, G. S., and Heath, J. R. (2010). Batch fabrication of highperformance planar patch-clamp devices in quartz. Adv. Mater. 22, 4622-4627.

Neher, E., and Sakmann, B. (1976). Single-channel currents recorded from membrane of denervated frog muscle fibers. Nature 260, 799-802.

Offenhausser, A., Bocker-Meffert, S., Decker, T., Helpenstein, R., Gasteier, P., Groll, J., Moller, M., Reska, A., Schafer, S., Schulte, P., and Vogt-Eisele, A. (2007). Microcontact printing of proteins for neuronal cell guidance. Soft Matter 3, 290-298.

Ogi, H., Fukunishi, Y., Nagai, H., Okamoto, K., Hirao, M., and Nishiyama, M. (2009). Nonspecific-adsorption behavior of polyethylenglycol and bovine serum albumin studied by $55-\mathrm{MHz}$ wireless-electrodeless quartz crystal microbalance. Biosens. Bioelectron. 24, 3148-3152.

Ong, W.-L., Tang, K.-C., Agarwal, A., Nagarajan, R., Luo, L.-W., and Yobas, L. (2007). Microfluidic integration of substantially round glass capillaries for lateral patch clamping on chip. Lab Chip 7, 1357-1366.

Ong, W.-L., Yobas, L., and Ong, W.-Y. (2006). A missing factor in chipbased patch clamp assay: gigaseal. $J$. Phys. 34, 187.
Palop, J. J., Chin, J., and Mucke, L. (2006). A network dysfunction perspective on neurodegenerative diseases. Nature 443, 768-773.

Pandey, S., Mehrotra, R., Wykosky, S., and White, M. H. (2004). Characterization of a MEMS BioChip for planar patch-clamp recording. Solid State Electron. 48, 2061-2066.

Pantoja, R., Nagarah, J. M., Starace, D. M., Melosh, N. A., Blunck, R., Bezanilla, F., and Heath, J. R. (2004). Silicon chip-based patchclamp electrodes integrated with PDMS microfluidics. Biosens. Bioelectron. 20, 509-517.

Patolsky, F. (2007). Detection, stimulation, and inhibition of neuronal signals with high-density nanowire transistor arrays. Science 313, 1100-1104.

Picollet, D. h. N., Sordel, T., Garnier, R. S., Sauter, F., Ricoul, F., Pudda, C., Marcel, F., and Chatelain, F. (2004). A silicon-based multi patch device for ion channel current sensing. Sens. Lett. 2, 91-94.

Pleasure, D., Hardy, M., Johnson, G., Lisak, R., and Silberberg, D. (1981). Oligodendroglial glycerophospholipid synthesis: incorporation of radioactive precursors into ethanolamine glycerophospholipids by calf oligodendroglia prepared by a Percoll procedure and maintained in suspension culture. J. Neurochem. 37, 452-460.

Priel, A., Gil, Z., Moy, V., Magleby, K., and Silberberg, S. (2007). Ionic requirements for membrane-glass adhesion and giga seal formation in patch-clamp recording. Biophys. J. 92, 3893-3900.

Py, C., Denhoff, M., Martina, M., Monette, R., Comas, T., Ahuja, T., Martinez, D., Wingar, S., Caballero, J., Laframboise, S., Mielke, J., Bogdanov, A., Luk, C., Syed, N., and Mealing, G. (2010). A novel silicon patch-clamp chip permits high-fidelity recording of ion channel activity from functionally defined neurons. Biotechnol. Bioeng. 107, 593-600.

Py, C., Mealing, G., Denhoff, M., Charrier, A., Monette, R., Comas, T., Ahuja, T., Martinez, D., Krantis, A., and Wingar, S. (2008). "A multiple recording patch clamp chip with integrated subterranean microfluidic channels for cultured neuronal networks," in Micro-Total Analysis Systems, San Diego, CA, 507-509.

Py, C., Salim, D., Monette, R., Comas, T., Fraser, J., Martinez, D., Martina, M., and Mealing, G. (2011). Cell to aperture interaction in patchclamp chips visualized by fluorescence microscopy and focused-ion beam sections. Biotechnol. Bioeng. 108, 1395-1403.

Qin, D., Xia, Y. N., and Whitesides, G. M. (2010). Soft lithography for microand nanoscale patterning. Nat. Protoc. 5, 491-502.

Ruoslahti, E., and Pierchbacker, M. (1986). Arg-Gly-Asp: a versatile cell recognition signal. Cell Motil. Cytoskeleton 44, 517-518.

Sachs, F., and Qin, F. (1993). Gated, ion-selective channels observed with patch pipettes in the absence of membranes: novel properties of a gigaseal. Biophys. J. 65, 1101-1107.

Scheiffele, P. (2003). Cell-cell signaling during synapse formation in the CNS. Annu. Rev. Neurosci. 26, 485-508.

Schmidt, C., Mayer, M., and Vogel, H. (2000). A chip-based biosensor for the functional analysis of single ion channels. Angew. Chem. Int. Ed. Engl. 39, 3137-3140.

Schnizler, K., Kuster, M., and Methfessel, C. (2003). The roboocyte: automated cDNA/mRNA injection and subsequent TEVC recording on Xenopus Oocytes in 96-well microtiter plates. Recept. Channels 9 , 41-48.

Seeley, W. W., Crawford, R. K., Zhou, J., Miller, B. L., and Greicius, M. D. (2009). Neurodegenerative diseases target large-scale human brain networks. Neuron 62, 42-52.

Seo, J., Ionescu-Zanetti, C., Diamond, J., Lal, R., and Lee, L. P. (2004). Integrated multiple patch-clamp array chip via lateral cell trapping junctions. Appl. Phys. Lett. 84, 1973-1975.

Shatz, C. (1990). Impulse activity and the patterning of connections during CNS development. Neuron 5, 745-756.

Sigworth, F. J., and Klemic, K. G. (2005). Microchip technology in ion-channel research. IEEE Trans. Nanobioscience 4, 121-127.

Song, S., Sjostrom, P. J., Reigl, M., Nelson, S., and Chklovskii, D. B. (2005). Highly nonrandom features of synaptic connectivity in local cortical circuits. PLoS Biol. 3, e68. doi:10.1371/journal.pbio.0030068

Sordel, T., Garnier-Raveaud, S., Sauter, F., Pudda, C., Marcel, F., De-Waard, M., Arnoult, C., Vivaudou, M., Chatelain, F., and Picollet-D'hahan, N. (2006). Hourglass SiO2 coating increases the performance of planar patch-clamp. J. Biotechnol. 125, 142-154.
Sordel, T., Kermarrec, F., Sinquin, Y., Fonteille, I., Labeau, M., SauterStarace, F., Pudda, C., de Crécy, F., Chatelain, F., De Waard, M., Arnoult, C., and Picollet-D'hahan, N. (2010). The development of high quality seals for silicon patch-clamp chips. Biomaterials 31, 7398-7410.

Sorkin, R., Greenbaum, A., David-Pur, M., Anava, S., Ayali, A., Ben-Jacob, E., and Hanein, Y. (2009). Process entanglement as a neuronal anchorage mechanism to rough surfaces. Nanotechnology 20, 015101.

Stett, A., Egert, U., Guenther, E., Hofmann, F., Meyer, T., Nisch, W., and Haemmerle, H. (2003a). Biological application of microelectrode arrays in drug discovery and basic research. Anal. Bioanal. Chem. 377, 486-495.

Stett, A., Burkhardt, C., Weber, U., van Stiphout, P., and Knott, T. (2003b). Cytocentering: a novel technique enabling automated cellby-cell patch clamping with the cytoptach chip. Recept. Channels 9, 59-66.

Stett, A., Bucher, V., Burkhardt, C., Weber, U., and Nisch, W. (2003c). Patch-clamping of primary cardiac cells with micro-openings in polyimide films. Med. Biol. Eng. Comput. 41, 233-240.

Suchyna, T., Markin, V., and Sachs, F. (2009). Biophysics and structure of the patch and the gigaseal. Biophys. J. 97, 738-747.

Taketani, M., and Baudry, M. (2006). Advances in Network Electrophysiology: Using Multi-Electrode Arrays. Secaucus, NJ: Springer.

Tang, K. C., Reboud, J., Kwok, Y. L., Peng, S. L., and Yobas, L. (2010). Lateral patch-clamping in a standard 1536well microplate format. Lab Chip 10 , 1044-1050

Unger, M. A., Chou, H. P., Thorsen, T., Scherer, A., and Quake, S. R. (2000). Monolithic microfabricated valves and pumps by multilayer soft lithography. Science 288, 113-116.

Vicario-Abejo'n, C., Collin, C., McKay, R., and Segal, M. (1998). Neurotrophins induce formation of functional excitatory and inhibitory synapses between cultured hippocampal neurons. J. Neurosci. 18, 7256-7271.

Vogt, A. K., Brewer, G. J., and Offenhausser, A. (2005). Connectivity patterns in neuronal networks of experimentally defined geometry. Tissue Eng. 11, 1757-1767.

Voicu, R., Faid, K., Farah, A. A., Bensebaa, F., Barjovanu, R., Py, C., and Tao, Y. (2007). Nanotemplating for twodimensional molecular imprinting. Langmuir 23, 5452-5458. 
Pye et al.

Patch-clamp array chip

Wang, X., and Li, M. (2003). Automated electrophysiology: high throughput of art. Assay Drug Lev. Technol. 1, 695-708.

Wheeler, B. C., and Brewer, G. J. (2010). Designing neural networks in calture. Proc. IEEE 98, 398-406.

Wheeler, B. C., Brewer, G. J., Branch, D. W., Chang, J., and Venkateswar, K. (1999). Rational design of in vito neural networks using patterned self-assembled monolayers. Abstr. Pap. Am. Chem. Soc. 217, 014-BTEC.

Witchel, H. (2010). Emerging trends in ion channel-based assays for predicting the cardiac safety of drugs. Idrugs 13, 90-96.

Wooden, M. A., Hamakawa, T., Takasaki, M., Lukowiak, K., and Syed, N. I. (1999). Trophic factorinduced plasticity of synaptic connections between identified
Lymnaea neurons. Learn. Mem. 6, 307-316.

Wooden, M. A., Munno, D. W., and Syed, N. (2002). Trophic factor-induced excitatory synaptogenesis involves postsynaptic modulation of ricotinic acetylcholine receptors. J. Newrosci. 22, 505-514.

Wyart, C., Ybert, C., Bourdieu, L., Herr, C., Prinz, C., and Chatenay, D. (2002). Constrained synaptic connectivity in functional mammalian neuronal networks grown on pattermed surfaces. J. Neurosci. Methods 117, 123-131.

Zhao, Y., She, C. L., Sawyer, D. B., Liao, R., and Chang, X. (2007). Simultaneous orentation and cellular force measurements in adult cardiac myocytes using three-dimensional polymeric microstructure.
Cell Motile. Cytoskieleton 64, 718-725.

Chou, Z., and Kans, H.-G. (2000). Patch clamp noise from seal impedance and the pipette capacitance. Ann. Int. Conf. IEEE Eng. Med. Biol. Soc. 12, 1679-1680.

Conflict of Interest Statement: The authors declare that the research was conducted in the absence of any commercial or financial relationships that could be construed as a potential conflict of interest.

Received: 13 July 2011; paper pending published: 29 July 2011; accepted: 05 September 2011; published online: 03 October 2011.

Citation: By C, Martina M, DiazQuijada GA, Luk CC, Martinez D,
Denhoff $M W$, Charier A, Comas T, Monette R, Krantis A, Syed NI and Mealing GAR (2011) From understanding rellula function to novel drug discovery: the role of planar patch-clamp array chip technology. Front. Pharmacol. 2:51. do: 10.3389/fphar.2011.00051

This article was submitted to Frontiers in Pharmacology of Ion Channels and Channelopathies, a specialty of Frontiers in Pharmacology.

Copyright (C) 2011 Dy, Martina, DiazQuijada, Luk, Martinez, Denhoff, Charier, Comas, Monette, Krantis, Syed and Mealing. This is an open-access artche subject to a nonexclusive license between the authors and Frontiers Media $S A$, which permits use, distribution and reproduction in other forums, provided the original authors and source are credted and other Frontiers conditions are complied with.

Frontiers in Pharmacology | Pharmacology of Ion Channels and Channelopathies

October 2011 | Volume 2 | Article 51 | 16 